\title{
Organic aerosol formation from the reactive uptake of isoprene epoxydiols (IEPOX) onto non-acidified inorganic seeds
}

\author{
T. B. Nguyen ${ }^{1}$, M. M. Coggon ${ }^{2}$, K. H. Bates ${ }^{2}$, X. Zhang ${ }^{1}$, R. H. Schwantes ${ }^{1}$, K. A. Schilling ${ }^{2}$, C. L. Loza ${ }^{2, *}$, R. \\ C. Flagan ${ }^{2,3}$, P. O. Wennberg ${ }^{1,3}$, and J. H. Seinfeld ${ }^{2,3}$ \\ ${ }^{1}$ Division of Geological and Planetary Sciences, California Institute of Technology, Pasadena, California, USA \\ ${ }^{2}$ Division of Chemistry and Chemical Engineering, California Institute of Technology, Pasadena, California, USA \\ ${ }^{3}$ Division of Engineering and Applied Science, California Institute of Technology, Pasadena, California, USA \\ *currently at: 3M Environmental Laboratory, 3M Center, Building 0260-05-N-17, St. Paul, Minnesota, USA
}

Correspondence to: T. Nguyen (tbn@caltech.edu)

Received: 10 October 2013 - Published in Atmos. Chem. Phys. Discuss.: 28 October 2013

Revised: 8 February 2014 - Accepted: 18 February 2014 - Published: 8 April 2014

\begin{abstract}
The reactive partitioning of $c$ is and trans $\beta$-IEPOX was investigated on hydrated inorganic seed particles, without the addition of acids. No organic aerosol (OA) formation was observed on dry ammonium sulfate (AS); however, prompt and efficient OA growth was observed for the $c i s$ and trans $\beta$-IEPOX on AS seeds at liquid water contents of 40 $75 \%$ of the total particle mass. OA formation from IEPOX is a kinetically limited process, thus the OA growth continues if there is a reservoir of gas-phase IEPOX. There appears to be no differences, within error, in the OA growth or composition attributable to the cis / trans isomeric structures. Reactive uptake of IEPOX onto hydrated AS seeds with added base $(\mathrm{NaOH})$ also produced high OA loadings, suggesting the $\mathrm{pH}$ dependence for OA formation from IEPOX is weak for AS particles. No OA formation, after particle drying, was observed on seed particles where $\mathrm{Na}^{+}$was substituted for $\mathrm{NH}_{4}^{+}$. The Henry's Law partitioning of IEPOX was measured on $\mathrm{NaCl}$ particles (ionic strength $\sim 9 \mathrm{M}$ ) to be $3 \times 10^{7} \mathrm{M} \mathrm{atm}^{-1}(-50 /+100 \%)$. A small quantity of OA was produced when $\mathrm{NH}_{4}^{+}$was present in the particles, but the chloride $\left(\mathrm{Cl}^{-}\right)$anion was substituted for sulfate $\left(\mathrm{SO}_{4}^{2-}\right)$, possibly suggesting differences in nucleophilic strength of the anions. Online time-of-flight aerosol mass spectrometry and offline filter analysis provide evidence of oxygenated hydrocarbons, organosulfates, and amines in the particle organic composition. The results are consistent with weak correlations between IEPOX-derived OA and particle acidity or liquid water observed in field studies, as the chemical system is nucleophile-limited and not limited in water or catalyst activity.
\end{abstract}

\section{Introduction}

A significant portion of the organic aerosol (OA) production from isoprene, a non-methane hydrocarbon emitted to the atmosphere in vast amounts, is attributed to the heterogeneous chemistry of isoprene epoxydiols (IEPOX) (Froyd et al., 2010; Chan et al., 2010; McNeill et al., 2012; Surratt et al., 2010; Hatch et al., 2011; Budisulistiorini et al., 2013; Pye et al., 2013). IEPOX, of which there are four isomeric forms (Scheme 1), is a second-generation low nitric oxide (NO) isoprene photooxidation product formed from the $\mathrm{OH}$-oxidation of particular isomers of isoprene hydroxy hydroperoxides (Paulot et al., 2009b). The mechanism for OA production from IEPOX has been proposed as ring-opening of the epoxide group, activated by proton transfer from a strong acid such as sulfuric acid $\left(\mathrm{H}_{2} \mathrm{SO}_{4}\right)$, followed by nucleophilic addition of available nucleophiles in the condensed phase, e.g., addition of water to produce tetrols, sulfate to produce organosulfates, and so on (Minerath et al., 2008; Eddingsaas et al., 2010; Surratt et al., 2010). This proposed mechanism has been corroborated by chamber investigations of particle acidity effects on OA formation (Surratt et al., 2007; Lin et al., 2012), wherein dry acidic seeds $\left(\mathrm{MgSO}_{4}: \mathrm{H}_{2} \mathrm{SO}_{4}, 1\right.$ : 1) prompted strong reactive uptake behavior from epoxides (Paulot et al., 2009b), compared to negligible uptake for dry, non-acidified seeds.

Recent field data suggest that the story might be more complex than described above, as weak correlations between particle acidity and the abundance of IEPOX particle-phase tracer products were observed in Southeastern USA sites 


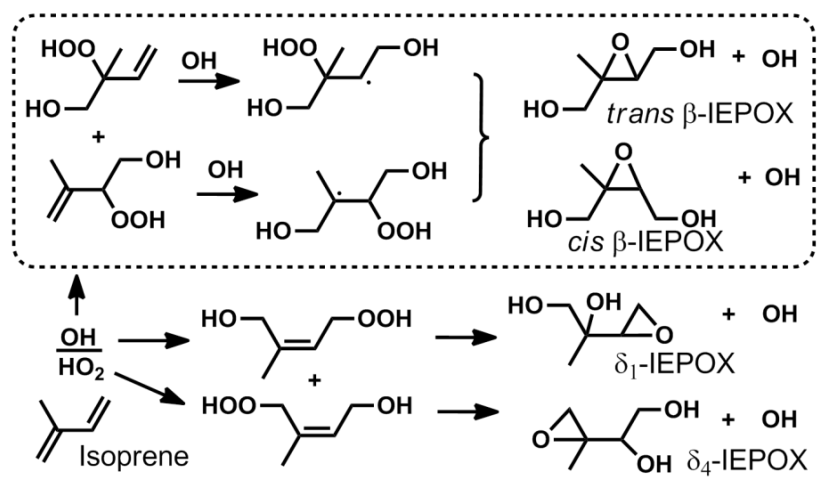

Scheme 1 Formation of IEPOX isomers, from relevant isoprene hydroxy hydroperoxide precursors, in the low-NO photooxidation of isoprene. The expected dominant pathway is shown inside the box. The naming convention is based on Paulot et al. (2009b).

(Lin et al., 2013; Budisulistiorini et al., 2013). It should be noted that the indirect definition of "particle acidity," which relies on charge balance of cations and anions, have several limitations and may not effectively represent the activity of $\mathrm{H}^{+}$in the aqueous phase of particles in some cases (Gregoire, 2013). Nevertheless, from the field observations, Lin and coworkers proposed that other factors may possibly modulate OA formation from IEPOX in conjunction with particle $\left[\mathrm{H}^{+}\right]$. One important distinction between previous chamber investigations, which have all been conducted under dry conditions (relative humidity, $\mathrm{RH}<5 \%$ ), and the Southeastern USA location is the prevalence of particle liquid water on the ammonium sulfate seeds. Water is a ubiquitous and abundant component of the atmosphere, therefore the effect of liquid water on the uptake of OA precursors has important implications for much of the globe. The crystalline ammonium sulfate seeds used in dry chamber experiments may not have adequate liquid water for IEPOX to partition into the aqueous phase, nor sufficient $\mathrm{H}^{+}, \mathrm{NH}_{4}^{+}$, and $\mathrm{SO}_{4}^{2-}$ activities to promote reactive uptake. Similarly, a particle with a large weight percent of $\mathrm{H}_{2} \mathrm{SO}_{4}$ may have a sizeable liquid water component, even at $\mathrm{RH}<5 \%$, due to the strong hygroscopicity of $\mathrm{H}_{2} \mathrm{SO}_{4}$ (Xiong et al., 1998), and the difference in reactive uptake of IEPOX may be due either to the differences in particle liquid water or the particle free acidity. In contrast, high concentrations of liquid water may cause dilution of aqueous ions, i.e., changing the acidity or ionic strength, which has been demonstrated to change the effective Henry's Law partitioning coefficient of glyoxal (Kampf et al., 2013). Despite these important interactions, the effect of liquid water on OA formation from IEPOX has not been systematically explored in the laboratory.

We report here the reactive uptake of two isomers of IEPOX, the cis and trans $\beta$-IEPOX (Paulot et al., 2009b), which together comprise more than $97 \%$ of the isomer distribution (Bates et al., 2014). We synthesized authentic stan- dards and observed the dark OA growth onto non-acidified and hydrated inorganic seeds at several particle liquid water concentrations. In the atmosphere, ammonium ions $\left(\mathrm{NH}_{4}^{+}\right)$ are one of the most abundant components of aerosols and considerable IEPOX-derived OA are observed, even when a dominant portion of the aerosols are charge-balanced, e.g., $\left[\mathrm{NH}_{4}^{+}\right]: 1 / 2 \times\left[\mathrm{SO}_{4}^{2-}\right]$ or $\left[\mathrm{NH}_{4}^{+}\right]:\left[\mathrm{NO}_{3}^{-}\right] \sim 1$ (Lin et al., 2013). The aqueous $\mathrm{NH}_{4}^{+}$may possibly act as catalyst for $\mathrm{OA}$ formation, as has been shown for a number of atmospherically important reactions (Noziere et al., 2009; Sareen et al., 2010; Ervens and Volkamer, 2010; Yu et al., 2011). We study reaction with $\mathrm{NH}_{4}^{+}$as a potential rate-limiting mechanism for the IEPOX reaction. The role of cation and anion compositions in the seed for OA formation is studied by using ammonium sulfate, ammonium chloride, sodium sulfate, and sodium chloride seeds.

\section{Materials and methods}

\subsection{Experimental procedures}

This work utilized a newly constructed $24 \mathrm{~m}^{3}$ FEP Teflon environmental chamber specifically reserved for low- $\mathrm{NO}_{\mathrm{x}}$ applications. The walls have not been in contact with strong acids and the chamber was operated in batch mode. Experiments were performed at room temperature $\left(23-24{ }^{\circ} \mathrm{C}\right)$ and in the dark. Prior to the start of experiments, the chamber was thoroughly flushed with dry, purified air until particle concentrations are $<0.01 \mu \mathrm{g} \mathrm{m}^{-3}$. For humid experiments, water vapor was injected until the desired relative humidity $(\mathrm{RH})$ was achieved in the chamber by flowing dry purified air over a Nafion membrane humidifier (FC200, Permapure LLC), which is kept moist by recirculating $27^{\circ} \mathrm{C}$ ultrapurified (18 M $\Omega$ ) water (Milli-Q, Millipore Corp). Temperature and RH were measured by a Vaisala HMM211 probe, calibrated with saturated salt solutions in the RH range of 11$95 \%$. For RH $<11 \%$, the water vapor content was quantified by chemical ionization mass spectrometry (Sect. 2.2.1).

Seed particles were injected by atomizing aqueous solutions $(0.06 \mathrm{M})$ of ammonium sulfate $\left(\left(\mathrm{NH}_{4}\right)_{2} \mathrm{SO}_{4}, \mathrm{AS}\right)$, sodium chloride $(\mathrm{NaCl})$, ammonium chloride $\left(\mathrm{NH}_{4} \mathrm{Cl}\right)$, or sodium sulfate $\left(\mathrm{Na}_{2} \mathrm{SO}_{4}\right)$ at $2100 \mathrm{hPa}$ of air into the chamber through a ${ }^{210} \mathrm{Po}$ neutralizer and water trap. All inorganic seeds were injected through a $30 \mathrm{~cm}$ custom-built wet-wall denuder kept at $90^{\circ} \mathrm{C}$, such that the seed particles enter the chamber hydrated. Liquid water is expected to evaporate from the seed particles according to the salt's efflorescence behavior (Lee and Hsu, 2000) at the RH of the chamber, e.g., in a dry chamber it is expected that the hydrated particles will enter the chamber fully dried. Particles were allowed to equilibrate until their volume concentrations are stable prior to organic injections.

Two isomers of isoprene epoxydiols (cis and trans $\beta$ IEPOX) were synthesized via procedures adapted from 
Zhang et al. (2012) and purified with normal-phase column chromatography until the estimated purity based on nuclear magnetic resonance (NMR) of the cis and trans $\beta$-IEPOX isomers are $99 \%$ and $>92 \%$, respectively. Details of the synthesis and NMR spectra are reported in Bates et al. (2014). Although the mole fractions of the impurities are low, their high volatility may lead to an over-represented abundance in the gas phase. For the cis isomer, we detected experimental interference from the volatile 1,4-dihydroxy-2-methyl-2butene (a precursor used in the synthesis), comprising 50\% of the vapor phase measured directly above a bulb of IEPOX droplets by chemical ionization mass spectrometry (CIMS, Sect. 2.2). In order to further purify before experiments were conducted, cis $\beta$-IEPOX droplets were purged with dry $\mathrm{N}_{2}$, and combined with $60^{\circ} \mathrm{C}$ heating for $>8 \mathrm{~h}$ until the measured impurity fraction dropped below $2 \%$ (Fig. S1 in the Supplement). After the additional purification, IEPOX was injected into the chamber by flowing a $5-8 \mathrm{~L} \mathrm{~min}^{-1}$ stream of dry purified air past several droplets in a clean glass bulb heated to $60^{\circ} \mathrm{C}$ for $2-4 \mathrm{~h}$. The mixtures of IEPOX and seed aerosols were allowed to equilibrate for $>1 \mathrm{~h}$. Most of the experimental conditions were repeated and were found to be reproducible within $15 \%$. We expect systematic error to dominate over the error of precision in this work.

\subsection{Analytical methods}

\subsubsection{Chemical ionization mass spectrometry (CIMS)}

Gas-phase IEPOX was measured with negative-ion chemical ionization mass spectrometry (CIMS) using $\mathrm{CF}_{3} \mathrm{O}^{-}$as the reagent ion, described in more detail previously (Crounse et al., 2006; Paulot et al., 2009a; St. Clair et al., 2010). The mass analyzer is a Varian triple-quadrupole spectrometer with unit mass resolution. Air is brought from the chamber using a $3 \mathrm{~mm}$ inner diameter perfluoroalkoxy (PFA) Teflon line with flow rate of $2.5 \mathrm{~L} \mathrm{~min}^{-1}$. Of the total chamber flow, a $145 \mathrm{~mL} \mathrm{~min}^{-1}$ analyte flow was sampled orthogonally through a glass critical orifice into the CIMS. The analyte flow was further diluted by a factor of 12 with dry $\mathrm{N}_{2}$ to minimize the interaction of water vapor from the chamber with the reagent ion in the ion-molecule flow region. The subsequent data analysis corrects for the dilution factor. The operational pressure and temperature were kept at $35.5 \mathrm{hPa}$ and $35^{\circ} \mathrm{C}$, respectively. The CIMS operated in a scanning MS mode ( $m / z$ 50-250) and tandem MS mode (MSMS). In MSMS mode, collisionally induced dissociation (CID) with $2.6 \mathrm{hPa}$ of $\mathrm{N}_{2}$ fragments analyte ions into product ions in the second quadrupole, following the ejection of neutral species. The MS cluster ion $\mathrm{C}_{5} \mathrm{H}_{10} \mathrm{O}_{3} \cdot \mathrm{CF}_{3} \mathrm{O}^{-}(\mathrm{m} / z$ 203) of IEPOX was used for quantification, due to the higher signal-to-noise $(\mathrm{S} / \mathrm{N})$ of this ion compared to MSMS ions. The MSMS product ion $\mathrm{C}_{5} \mathrm{H}_{9} \mathrm{O}_{3} \cdot \mathrm{CF}_{2} \mathrm{O}^{-}(\mathrm{m} / \mathrm{z} \quad 203 \rightarrow \mathrm{m} / \mathrm{z}$ 183), found to be unique to IEPOX in the isoprene OH-oxidation system, was used to differentiate IEPOX from the isobaric isoprene hydroperoxide (ISOPOOH), which has been documented to yield mainly $\mathrm{m} / \mathrm{z} 63$ and a negligible amount of $\mathrm{m} / \mathrm{z} 183$ upon CID (Paulot et al., 2009b). ISOPOOH $(\mathrm{m} / z 203 \rightarrow$ $m / z 63$ ), was not expected, nor observed, during IEPOX injections.

CIMS calibrations of cis and trans $\beta$-IEPOX were performed by separately atomizing dilute $(1-3 \mathrm{mM})$ solutions of each isomer with equimolar concentrations of hydroxyacetone, used as an internal standard, into the chamber through a $15 \mathrm{~cm}$ PFA Teflon transfer line for a few hours. During synthesis, NMR analysis showed that IEPOX was stable in water solution for many hours if no acid was present, so decay of IEPOX in the atomizer solution was not expected over the course of the calibration experiment. Toluene was used as a tracer to obtain the exact volume of the Teflon bag for each calibration experiment. A measured volume of toluene $(6 \mu \mathrm{L})$ was injected into a clean glass bulb with a microliter syringe (Hamilton) and quantitatively transferred into the chamber with a $5 \mathrm{~L} \mathrm{~min}^{-1}$ stream of dry purified air. The gas-phase toluene was monitored by commercial gas chromatograph with flame-ionization detector (GC-FID, Hewlett-Packard $6890 \mathrm{~N}$ ) using a calibrated HP-5 column $(15 \mathrm{~m}, 0.53 \mathrm{~mm}$ i.d.). The initial chamber temperature was $35^{\circ} \mathrm{C}$, and the temperature was ramped until $45^{\circ} \mathrm{C}$ or until no increase of IEPOX signal was observed in the CIMS. The atomized solution was weighed before and after atomization. Each sensitivity determination was repeated at least twice. The sensitivities of the IEPOX isomers were calculated from the ratio of the normalized ion counts (with respect to the reagent ion signal) to the number of atomized moles. Small amounts of nucleated organic aerosols were observed in the chamber from the atomization, as measured by a scanning mobility particle sizer (Sect. 2.2.3) and that volume concentration was subtracted from the theoretical moles of IEPOX (corrections of $<1 \%$ ). Based on their calculated dipole moments and average polarizability, the cis isomer was expected to have a sensitivity of $\sim 1.6$ times greater than the trans isomer (Paulot et al., 2009b), and we found the sensitivity of the cis isomer to be a factor of 1.8 greater than the trans isomer in the MS mode. The difference between the two ratios is within the error of the sensitivity determination.

Additionally, several mixing ratios of water vapor were introduced into the CIMS ion-molecule region to measure the water dependence of the IEPOX detection. Water vapor was quantified by Fourier-transform infrared spectroscopy (FTIR, Nicolet Magna-IR 560) with a $19 \mathrm{~cm}$ pathlength quartz cell. Spectral fitting was performed using the HITRAN spectral database (Rothman et al., 2009) and the nonlinear fitting software NLM4 developed by Griffith (1996). In the low$\mathrm{RH}$ range, outside the calibration limit of the membrane $\mathrm{RH}$ probe, the CIMS water ions $\mathrm{H}_{2} \mathrm{O} \cdot{ }^{13} \mathrm{CF}_{3} \mathrm{O}^{-}(m / z$ 104) and $\left(\mathrm{H}_{2} \mathrm{O}\right)_{2} \cdot \mathrm{CF}_{3} \mathrm{O}^{-}(\mathrm{m} / \mathrm{z} 121)$ were used to quantify water vapor concentration in the chamber after calibration of water vapor with FT-IR. These ions provide excellent sensitivity to water and linearity in the $20-3500 \mathrm{ppm}$ range in the CIMS 
ion molecule flow region (corresponding to $1-100 \% \mathrm{RH}$ in the chamber at $24^{\circ} \mathrm{C}$, before CIMS dilution). No water dependence in the detection of the IEPOX ions was observed within the range of water vapor observed by CIMS.

In order to quantify the gas-phase concentrations of IEPOX, the CIMS signal was corrected to account for the RH-dependent wall losses of IEPOX. The interactions of IEPOX with chamber walls have not been previously characterized, although those of its $\mathrm{C}_{4}$ analog have been reported (Loza et al., 2010). IEPOX wall loss experiments were conducted at $\mathrm{RH}=3 \%, 46 \%$, and $69 \%$, as described in Section 2.1 , continuously for $5-10 \mathrm{~h}$. Figure S2 shows that the wall losses of IEPOX on non-acidic walls were negligibly small $\left(\sim 0.4 \% \mathrm{~h}^{-1}\right.$ at RH $\left.69 \%\right)$, within the error of CIMS measurements.

\subsubsection{Aerosol mass spectrometry (AMS)}

Online particle composition was measured with a highresolution time-of-flight aerosol mass spectrometer (ToFAMS, Aerodyne Research Inc.). The ToF-AMS was operated in $\mathrm{V}$ mode $(R \sim 2000$ at $m / z$ 200) and $\mathrm{W}$ mode $(\mathrm{R} \sim 3000$ 4000 at $\mathrm{m} / z$ 200). Prior to experiments, the ToF-AMS ionization efficiency was calibrated using size-selected $350 \mathrm{~nm}$ ammonium nitrate particles. The ToF-AMS monitored the content of ammonium $\left(\mathrm{NH}_{4}^{+}\right)$, sulfate $\left(\mathrm{SO}_{4}^{2-}\right)$ and other nonrefractory ions throughout the course of the experiment. The ammonium to sulfate ratio did not change over the course of the experiment. Gas interferences and elemental ratios were calculated using the fragmentation tables developed by Allan et al. (2004) and Aiken et al. (2008). Data were analyzed in IGOR Pro 6.31 (WaveMetrics, Inc.) using the SQUIRREL $\vee 1.51 \mathrm{H}$ and PIKA $\vee 1.10 \mathrm{H}$ analysis toolkits. Total concentration of organics $\left(\mu \mathrm{g} \mathrm{m}^{-3}\right)$ was calculated by summing the nitrate-equivalent masses of each high-resolution ion correlated with the organic fraction from the V-mode data.

Particles were sampled through a $130 \mathrm{~cm}$ Nafion membrane diffusion drier (MD-110, Permapure LLC) to avoid flow obstructions from wet particles over time, at a flow rate of $0.084 \mathrm{~L} \mathrm{~min}^{-1}$. It is expected that drying the particles may introduce particle or organic line losses in the drier tube and change the particle bounce characteristics on the AMS vaporizer plate. These perturbations may be corrected by applying a collection-efficiency (CE) factor. It was demonstrated that organic aerosol particles with higher water content have very low bounce probability, which corresponds to a CE of unity (Matthew et al., 2008; Docherty et al., 2013). Comparatively, dry particles have much lower CE $(\sim 0.25$ for pure, dry AS) due to the high bounce rate. The CE of IEPOXderived organic aerosol-coated particles was calculated by measuring the mass concentrations of organics, sulfate, and ammonium of the wet particles without a drier, wherein CE was assumed to be unity and line losses assumed to be negligible, and comparing with measurements made through a drier. We observe a CE of 0.75 for all conditions in this work, which is consistent with the collection efficiency of organic aerosols measured previously (Docherty et al., 2013). Further, it is expected that drying particles, relevant to the hydration/evaporation cycles of aerosols in nature, may lead to enhanced interactions between organic and inorganic compounds (De Haan et al., 2011; Nguyen et al., 2012), irreversibly forming OA.

\subsubsection{Particle size and number concentration}

Particle size and number concentrations were measured with a scanning mobility particle sizer (SMPS), comprised of a custom-built differential mobility analyzer (DMA) coupled to a commercial butanol-based condensation particle counter (CPC, TSI Inc.). The SMPS particle size measurement was calibrated with polystyrene latex (PSL) spheres. The particles entering the chamber have a static polydisperse distribution, with peak dry particle diameter distributions in the range of $50-100 \mathrm{~nm}$. The sample air flow was not dried in humid experiments. Particle mass concentrations were corrected for RH- and size-dependent wall losses. The mass concentration of particles typically ranged from $65-90 \mu \mathrm{g} \mathrm{m}^{-3}$ for all experiments, using a particle density of $1.2 \mathrm{~g} \mathrm{~cm}^{-3}$.

For AS-based experiments, the particle liquid water content was calculated based on the size-dependent hygroscopicity of AS (Biskos et al., 2006; Hu et al., 2010). For each particle diameter bin measured by SMPS, a theoretical dry diameter was calculated based on size-dependent literature growth factor data at the $\mathrm{RH}$ of the experiment. The difference in the wet (measured) and dry (calculated) integrated area of the mass distribution yielded the liquid water concentration in $\mathrm{g} \mathrm{m}^{-3}$. Similarly, the percent of liquid water content is calculated as $\% \mathrm{LWC}=100 \% \times\left(\mathrm{V}_{\text {wet }}-\mathrm{V}_{\text {dry }}\right) / \mathrm{V}_{\text {wet }}$, using the predicted wet and dry diameters.

Particle wall loss characterizations were performed for AS seeds at $\mathrm{RH}=3 \%, 20 \%, 50 \%$, and $80 \%$ prior to the start of the experimental series to correctly quantify the mass concentrations of particles as a function of time. It was assumed that the loss rates of AS were representative for particles of different composition. Seed aerosols were atomized into the dry or humid chambers in the dark, allowed to stabilize, and particle size and number concentrations were measured for $>12 \mathrm{~h}$. The particle correction method that accounts for wall loss has been discussed in detail previously (Loza et al., 2012).

\subsubsection{Filter collection and analysis}

Offline OA composition analysis was performed by ultrahigh performance liquid chromatography time-of-flight electrospray ionization mass spectrometry (UPLC/ESI-ToFMS). Aerosol samples were collected onto Teflon membrane filters (Millipore, $1 \mu \mathrm{m}$ pore), pulled at a $20 \mathrm{~L} \mathrm{~min}^{-1}$ flow through an activated charcoal denuder to remove the volatile and semivolatile components. Each filter was extracted with 
methanol (Fisher, Optima grade, $\geq 99.9 \%$ ) by ultrasonication for $15 \mathrm{~min}$ in a $20 \mathrm{~mL}$ scintillation vial. The filtered extracts were blown dry under a gentle stream of ultra-highpurity $\mathrm{N}_{2}$. The residue was reconstituted with $150 \mu \mathrm{L}$ of $50: 50 \mathrm{v} / \mathrm{v}$ acetonitrile (Fisher Optima grade, $\geq 99.9 \%$ ) and water (Milli-Q).

Extracts were analyzed by a Waters Xevo G2-S UPLC/ESI-ToF-MS equipped with an Acquity $\mathrm{CSH} \mathrm{C}_{18}$ column $(1.7 \mu \mathrm{m}, 2.1 \times 100 \mathrm{~mm})$. The solvents used for gradient elution were acetonitrile (Fisher Optima grade, $\geq 99.9 \%$ ) and water with a $0.1 \%$ formic acid spike (solvent "A"). The flow rate was held at $0.5 \mathrm{~mL} \mathrm{~min}^{-1}$. Accurate mass correction was completed by a lock spray of leucine enkephalin (0.61 ng $\mu \mathrm{L}^{-1}$ in $50: 50 \mathrm{v} / \mathrm{v}$ acetonitrile/water with $0.1 \%$ formic acid). The ESI source was operated in negative mode, where most analytes are ionized by deprotonation and measured as $[\mathrm{M}-\mathrm{H}]^{-}$. Ionic molecular formulas were determined from accurate masses (mass resolution of 60000 at $\mathrm{m} / \mathrm{z}$ 400) using the elemental composition tool in Mass Lynx. Control filters (no particles) and laboratory controls (seeds only) were analyzed in the same manner.

\section{Results and Discussion}

\subsection{Reactive uptake of $c$ is and trans $\beta$-IEPOX onto ammonium sulfate seeds}

\subsubsection{Liquid water content of seeds}

Figure 1 shows the time profile for the organic aerosol (OA) growth corresponding to reactive uptake of the trans $\beta$ IEPOX onto ammonium sulfate (AS) seeds at two RH conditions, dry (LWC $\sim 0 \%$ ) and RH $57 \%$ (LWC 55\%). The traces shown in Fig. 1 are representative of uptake behavior for both isomers on the experimental timescale. For RH conditions above the ammonium sulfate (AS) efflorescence point tested in this work $\left(\mathrm{E}_{\mathrm{RH}} \sim 35 \%\right.$, (Biskos et al., 2006)), prompt and efficient OA growth onto AS seeds was observed for both IEPOX isomers. No OA growth was observed when the AS seeds were dry, in good agreement with other reports (Lin et al., 2012, Surratt et al., 2010).

The OA growth from IEPOX did not halt after the end of the gas-phase injection period (Fig. 1, solid black line), even after periods of $>2 \mathrm{~h}$ (Fig. S3, top panel). This behavior is indicative of a non-equilibrium process, as the addition of nucleophiles is not reversible after the rate-limiting step of IEPOX activation (Eddingsaas et al., 2010). The formation of low-volatility compounds should continue as long as a reservoir of gas-phase IEPOX is available. The series of expected reactions leading to the formation of ring-opening products (ROP) is shown below, illustrated using a general proton donor $(\mathrm{AH})$ and nucleophile $(\mathrm{Nu})$.

$$
\begin{aligned}
& \operatorname{IEPOX}_{(\mathrm{g})} \leftrightarrows \operatorname{IEPOX}_{(\mathrm{aq})}, \mathrm{K}_{\mathrm{H}} \\
& \operatorname{IEPOX}_{(\mathrm{aq})}+\mathrm{AH} \leftrightarrows \mathrm{IEPOX}-\mathrm{H}^{+}+\mathrm{A}_{-\mathrm{H}}, \mathrm{k}_{\mathrm{AH}}
\end{aligned}
$$

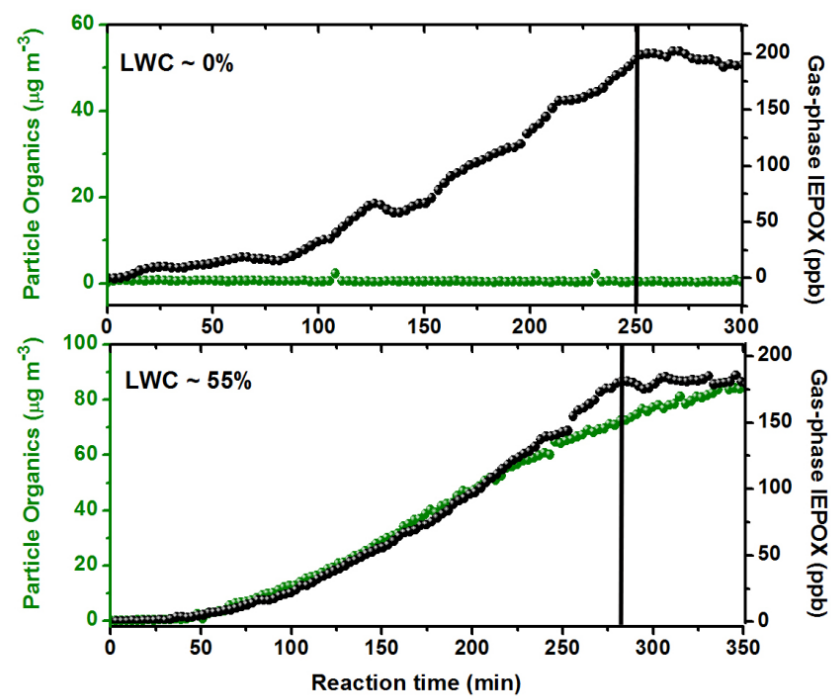

Fig. 1. Typical uptake experiment results as a function of time, shown for trans isomer, at dry (top) and humid (bottom) conditions with the corresponding percent of liquid water content (LWC). The solid black line indicates when IEPOX injection stopped and the mixture was allowed to equilibrate. Double $y$ axes correspond to traces of the same color.

$$
\begin{aligned}
& \text { IEPOX }-\mathrm{H}^{+}+\mathrm{Nu} \rightarrow \mathrm{ROP}-\mathrm{H}^{+}, \mathrm{k}_{\mathrm{Nu}} \\
& \mathrm{ROP}-\mathrm{H}^{+}+\mathrm{A}_{-\mathrm{H}} \rightarrow \mathrm{ROP}+\mathrm{AH}, \mathrm{k}_{\text {neutral }}
\end{aligned}
$$

For a solution with low $\mathrm{AH}$ and $\mathrm{Nu}$ activity, the equilibrium accommodation of IEPOX into the aqueous phase, described by the Henry's Law coefficient of IEPOX $\left(\mathrm{K}_{\mathrm{H}}\right)$, can be measured in isolation. Henry's Law may not be an appropriate description of the IEPOX reactive uptake experiments performed on the liquid water of suspended aerosols, as the aerosol water layers represent highly non-ideal solutions and the OA formation is kinetically limited. The OA formation mechanism may include contributions from reactions other than Reactions (1-4). To a first-order approximation, total OA mass formed from gas-phase reactive uptake of IEPOX will be a function of aqueous IEPOX concentration, nucleophile activity, and catalyst activity.

For the sake of comparison between experiments, it is useful to have a metric that includes the ratio of OA formed to gas-phase IEPOX injected and accounts for the variability in the size and number of injected seeds between experiments, which is reflected by the calculated aerosol water at different $\mathrm{RH}$. We define here a reactive partitioning coefficient ( $\left.\Phi_{\mathrm{OA} / \mathrm{IEPOX}}\right)$, calculated similarly to an effective Henry's Law coefficient, and thus having the same units (Seinfeld and Pandis, 2006):

$\Phi_{\mathrm{OA} / \mathrm{IEPOX}}=\left(C_{\mathrm{OA}} / C_{\mathrm{IEPOX}}\right) /\left[10^{-6} \cdot R \cdot T \cdot P_{\mathrm{LWC}}\right]$,

where $\left(C_{\mathrm{OA}} / C_{\mathrm{IEPOX}}\right)$ is the mass concentration ratio of the IEPOX-derived organic aerosol (dried), measured by ToFAMS, and the gas-phase IEPOX, measured by negative-ion 
Table 1. Summary of results from representative reactive uptake experiments onto ammonium sulfate seeds. Mean results from Lin et al. (2012) are shown for comparison.

\begin{tabular}{|c|c|c|c|c|c|c|c|c|}
\hline Exp. index & IEPOX isomer & Seed composition & $\mathrm{RH}(\%)$ & Particle $\mathrm{pH}^{*}$ & Seed $\left(\mu \mathrm{g} \mathrm{m}^{-3}\right)$ & $P_{\text {LWC }}\left(\mathrm{g} \mathrm{m}^{-3}\right)$ & $C_{\mathrm{OA}} / C_{\mathrm{IEPOX}}$ & $\begin{array}{l}\Phi_{\mathrm{OA} / \mathrm{IEPOX}} \\
\left(\mathrm{M} \mathrm{atm}^{-1}\right)\end{array}$ \\
\hline 1 & cis & $\left(\mathrm{NH}_{4}\right)_{2} \mathrm{SO}_{4}$ & 3 & - & 70 & $<1 \times 10^{-6}$ & $5.04 \times 10^{-4}$ & - \\
\hline 2 & cis & $\left(\mathrm{NH}_{4}\right)_{2} \mathrm{SO}_{4}$ & 42 & 3.67 & 91 & $3.74 \times 10^{-5}$ & 0.102 & $1.15 \times 10^{8}$ \\
\hline 3 & cis & $\left(\mathrm{NH}_{4}\right)_{2} \mathrm{SO}_{4}$ & 50 & 3.74 & 92 & $4.79 \times 10^{-5}$ & 0.118 & $1.01 \times 10^{8}$ \\
\hline 4 & cis & $\left(\mathrm{NH}_{4}\right)_{2} \mathrm{SO}_{4}$ & 86 & 3.90 & 81 & $5.68 \times 10^{-5}$ & 0.179 & $4.00 \times 10^{7}$ \\
\hline 5 & trans & $\left(\mathrm{NH}_{4}\right)_{2} \mathrm{SO}_{4}$ & 2 & - & 65 & $<1 \times 10^{-6}$ & $4.74 \times 10^{-4}$ & - \\
\hline 6 & trans & $\left(\mathrm{NH}_{4}\right)_{2} \mathrm{SO}_{4}$ & 39 & 3.65 & 82 & $3.44 \times 10^{-5}$ & 0.090 & $1.06 \times 10^{8}$ \\
\hline 7 & trans & $\left(\mathrm{NH}_{4}\right)_{2} \mathrm{SO}_{4}$ & 57 & 3.77 & 89 & $4.64 \times 10^{-5}$ & 0.095 & $8.44 \times 10^{7}$ \\
\hline 8 & trans & $\left(\mathrm{NH}_{4}\right)_{2} \mathrm{SO}_{4}$ & 81 & 3.88 & 88 & $6.14 \times 10^{-5}$ & 0.115 & $7.66 \times 10^{7}$ \\
\hline 9 & trans & $\left(\mathrm{NH}_{4}\right)_{2} \mathrm{SO}_{4}+\mathrm{NaOH}, \mathrm{pH}=7$ & 70 & $\sim 5.5$ & 84 & $5.33 \times 10^{-5}$ & 0.090 & $6.89 \times 10^{7}$ \\
\hline $\begin{array}{l}\text { Lin et } \\
\text { al. (2012) }\end{array}$ & cis & $\mathrm{MgSO}_{4}+\mathrm{H}_{2} \mathrm{SO}_{4}(1: 1)$ & $<5$ & $\sim-10$ & 48 & $1.62 \times 10^{-5 * *}$ & 0.058 & $1.47 \times 10^{8}$ \\
\hline
\end{tabular}

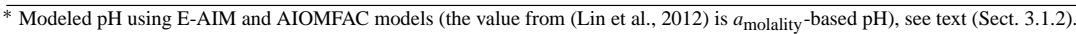

** Based on hygroscopicity of $\mathrm{H}_{2} \mathrm{SO}_{4}$ at $\mathrm{RH} 5 \%$, assumed growth factor 1.15, Xiong et al. (1998).

CIMS, $P_{\text {LWC }}$ is the liquid water content of the inorganic aerosols prior to IEPOX introduction $\left(\mathrm{g} \mathrm{m}^{-3}\right), R$ is the ideal gas constant ( $\mathrm{atm} \mathrm{L} \mathrm{mol}{ }^{-1} \mathrm{~K}^{-1}$ ), $T$ is the temperature (K), and $10^{-6}$ is a conversion factor $\left(\mathrm{m}^{3} \mathrm{~cm}^{-3}\right)$. $\Phi_{\text {OA/IEPOX }}$ includes the contribution from Henry's Law equilibrium partitioning of IEPOX (Reaction R1), and thus is an upper limit for the effective Henry's Law constant.

We observe that $\Phi_{\mathrm{OA} / \mathrm{IEPOX}}$ was not time-dependent when both IEPOX and OA were increasing, as the ratio $C_{\mathrm{OA}} / C_{\mathrm{IEPOX}}$ stabilized when OA grew in response to gasphase IEPOX (Fig. S3) but increased after IEPOX injection stopped. The stabilized ratio is used for $\Phi_{\mathrm{OA} / \mathrm{IEPOX}}$ calculations to compare between experiments. $P_{\mathrm{LWC}}$ did not have a significant time dependence due to a stable particle volume distribution before IEPOX gas-phase injections. The uncertainties in the accuracy of the $\Phi_{\mathrm{OA} / \mathrm{IEPOX}}$ and $\mathrm{K}_{\mathrm{H}}$ measurements were estimated to be $-50 \%$ and $+100 \%$, compounded from the uncertainties in the calculated CIMS sensitivities, liquid water fraction, AMS organic mass determinations, and other measurements.

A summary of $\Phi_{\mathrm{OA} / \mathrm{IEPOX}}$ and other values is given in Table 1 for all AS-based uptake experiments. Figure 2 shows $\Phi_{\text {OA/IEPOX }}$, as a function of particle liquid water, for the $c i s$ and trans $\beta$-IEPOX uptake onto hydrated AS. A trend of decreasing $\Phi_{\mathrm{OA} / \mathrm{IEPOX}}$ with increasing LWC was reproducibly observed, despite the uncertainty range in the $\Phi_{\mathrm{OA} / \mathrm{IEPOX}}$ determinations. The suppression of $\Phi_{\mathrm{OA} / \mathrm{IEPOX}}$ as a function of added water is likely due to dilution. For example, high aerosol sulfate concentrations may cause a "salting-in" effect for IEPOX, or other water-soluble organic compounds (Kampf et al., 2013), which is inversely proportional to water content. Higher water may also reduce the $\left[\mathrm{H}^{+}\right]$, although the dependence of the reaction on catalyst concentrations is not expected to be high. Additionally, higher $P_{\text {LWC }}$ dilutes the aqueous IEPOX and nucleophile concentrations in the aerosol liquid water, which reduce the rate of the chemical reaction as these species are direct reagents. The dilution ef-

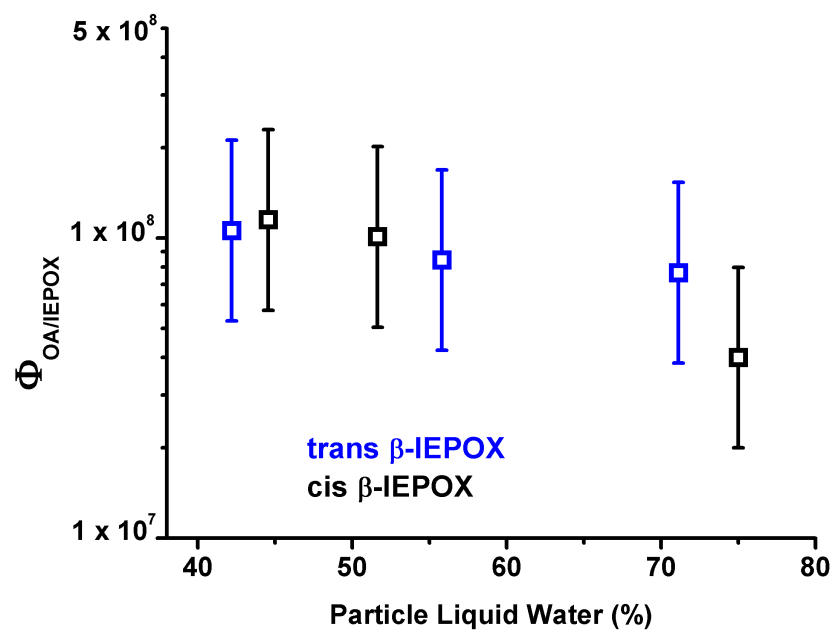

Fig. 2. Reactive partitioning coefficients $\left(\Phi_{\mathrm{OA} / \mathrm{IEPOX}}\right)$ during the gas-phase IEPOX injection phase for the trans and cis isomers as a function of the particle liquid water concentration. Error bars indicate experimental uncertainty as described in the text.

fect from increasing the pure water fraction at a fixed ion content (moles of $\mathrm{NH}_{4}^{+}$and $\mathrm{SO}_{4}^{2-}$ ) is in contrast to a modeled increase in OA mass in areas with high "anthropogenic water", in other words, mixtures of water-soluble compounds found in urban regions (Carlton and Turpin, 2013). In the atmosphere, the partitioning of anthropogenic gases like $\mathrm{NH}_{3}$ and $\mathrm{SO}_{2}$ will simultaneously impact aqueous acidity and inorganic concentration and thus may lead to enhanced OA formation in areas with higher $P_{\mathrm{LWC}}$.

\subsubsection{Particle acidity}

As the decrease of $\Phi_{\mathrm{OA} / \mathrm{IEPOX}}$ with increasing liquid water content may be due to more than one factor, an experiment was carried out to isolate the effect of $\mathrm{pH}$. In experiment 9 (Table 1), the AS solution was neutralized with a strong base 
$(\mathrm{NaOH})$ until the atomizer solution reached $\mathrm{pH}=7$. Solutions of AS without additives had $\mathrm{pH} \sim 5.5$ before atomization because, although no strong acid was present, $\mathrm{H}^{+}$is expected to be present in small quantities based on the dissociation equilibria of inorganics, such as the bisulfate/sulfate dissociation, and dissolution of $\mathrm{CO}_{2}$. An enhancement in the acidity of the particle may result from a smaller volume of water in the particle and/or through loss of $\mathrm{NH}_{3}$ upon atomization. In the case of a fully hydrated AS particle, the $\mathrm{pH}$ in the particle is predicted to be $\mathrm{pH} \sim 4$ using the E-AIM Model (Clegg et al., 1998), and modeled $\mathrm{pH}$ values in the particle for all AS-based experiments are shown in Table 1. As the $\mathrm{pH}$ values of the particles in this work are derived using inorganic models, the values obtained may include any uncertainties inherent in the models, including uncertainties in the gas/particle partitioning of $\mathrm{NH}_{3}$, hygroscopicity of salts, and/or acid dissociation equilibria. When the RH is below the deliquescence point of AS, the $\mathrm{pH}$ was estimated by calculating a concentration factor from the $P_{\mathrm{LWC}}$ at the lower RH. It is expected that atomization will also lead to slightly lower $\mathrm{pH}$ for the base-neutralized atomizer solution, so the particle may have $\mathrm{pH}<7$. However, adding $\mathrm{NaOH}$ above neutralization to counter this effect may induce side reactions such as base-catalyzed epoxide opening and $\mathrm{OH}^{-}$nucleophilic addition (Solomons and Fryhle, 2004). $\mathrm{NaOH}$ is not explicitly treated in the E-AIM and AIOMFAC (Zuend et al., 2008) inorganic models, therefore, it was assumed that atomization of the AS $+\mathrm{NaOH}$ solution may lead to, at most, the same enhancement factor that occurred for the $\mathrm{pH}$ of the pure AS solutions.

Figure 3 shows that $\Phi_{\text {OA/IEPOX }}$ for the trans $\beta$-IEPOX + AS system decreases slightly as $\mathrm{pH}$ is increased, reaching a plateau above $\mathrm{pH} \sim 4$. We note that any perceived change is within the error of the measurement, however, it is clear that the trend of $\Phi_{\mathrm{OA} / \mathrm{IEPOX}}$ with $\mathrm{pH}$ is minor. These results differ from those of Eddingsaas et al. (2010), who observed a linear increase of epoxide reaction rate with $\mathrm{H}^{+}$activity. Eddingsaas et al. (2010) used $\mathrm{H}_{2} \mathrm{SO}_{4} / \mathrm{Na}_{2} \mathrm{SO}_{4}$ solutions, and thus the differences in observations may be entirely due to the high $\mathrm{NH}_{4}^{+}$activity in the AS particles employed in this work. The data suggest that when $\left[\mathrm{H}^{+}\right]$is small, $\mathrm{NH}_{4}^{+}$may activate reactions leading to $\mathrm{OA}$ formation, similarly to its catalytic activity toward glyoxal (Noziere et al., 2009), methylglyoxal (Sareen et al., 2010), and other carbonyls (Nguyen et al., 2013, Bones et al., 2010). Interestingly, $\mathrm{pH}>4$ is the range where $\mathrm{NH}_{4}^{+}$catalysis is most efficient. This is demonstrated by a stable reactivity of the $\mathrm{NH}_{4}^{+}$-catalyzed reaction to generate brown carbon from limonene $\mathrm{SOA}$ at $\mathrm{pH} 4-9$, but a sharp decline of reactivity below pH 4 (Nguyen et al., 2012). As the $\mathrm{H}^{+}$and $\mathrm{NH}_{4}^{+}$ions are reactive toward organics in low-moderate and moderate-high $\mathrm{pH}$ ranges, respectively, the resulting $\mathrm{pH}$ dependence may appear to be weak in AScontaining seeds. The dual reactivities of $\mathrm{H}^{+}$and $\mathrm{NH}_{4}^{+}$to-

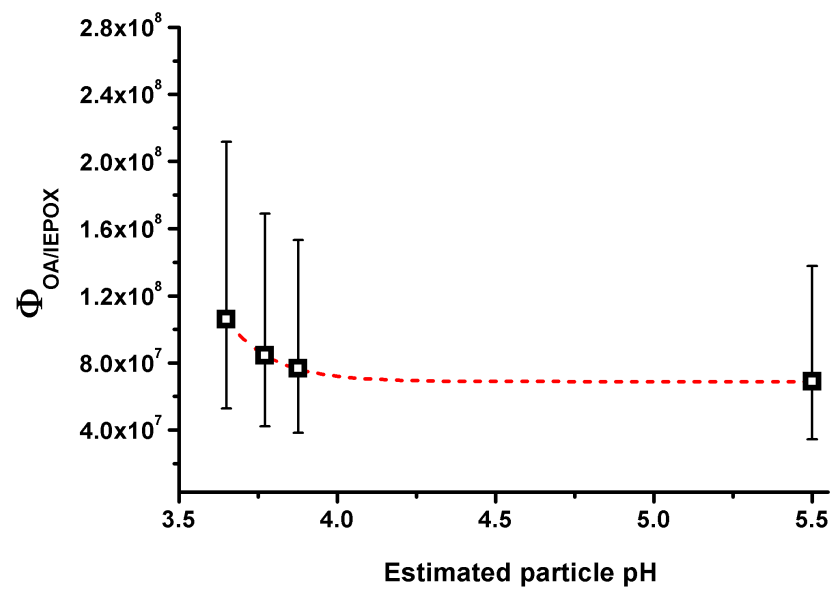

Fig. 3. $\Phi_{\mathrm{OA} / \mathrm{IEPOX}}$ for the trans $\beta$-IEPOX isomer as a function of the modeled particle $\mathrm{pH}$.

ward IEPOX is expected to be important in nature, as $\mathrm{NH}_{4}^{+}$based seeds are abundant.

In comparison, the $\mathrm{MgSO}_{4}: \mathrm{H}_{2} \mathrm{SO}_{4}$ particles at $\mathrm{RH}<5 \%$ in the work of Lin et al. (2012) are strongly acidic. These particles are predicted to have a non-negligible amount of water due to the large hygroscopicity of $\mathrm{H}_{2} \mathrm{SO}_{4}$ - and indeed, acidity in particles is not a useful concept if water is not present. At $\mathrm{RH}=0-5 \%$, pure $\mathrm{H}_{2} \mathrm{SO}_{4}$ particles have a growth factor of 1.1-1.2 (Xiong et al., 1998). Assuming a growth factor of 1.15 , and taking into consideration the inorganic seed mass concentration, we calculated $P_{\mathrm{LWC}}$ for the mean results in Lin et al. (2012), shown in Table 1. The AIOMFAC Model (Zuend et al., 2008; Zuend et al., 2011) was used to estimate the $\mathrm{pH}$ based on the molal activity of $\mathrm{H}^{+}$in the $\mathrm{MgSO}_{4}: \mathrm{H}_{2} \mathrm{SO}_{4}(1: 1)$ particle. The calculated $\mathrm{pH}$ is $\sim-10$ and the corresponding mean $\Phi_{\mathrm{OA} / \mathrm{IEPOX}}$ is $\sim 1.5 \times 10^{8} \mathrm{M} \mathrm{atm}^{-1}$ for cis $\beta$-IEPOX (the trans isomer was not studied). $\Phi_{\mathrm{OA} / \mathrm{IEPOX}}$ for the acidic $\mathrm{MgSO}_{4}$ seeds is slightly higher than, but within the error of, the $\Phi_{\text {OA/IEPOX }}$ values for non-acidified AS seeds when a small amount of water is present (RH $\sim 40 \%)$. This comparison is meant to be qualitative and subject to uncertainty because the experiments were not performed under the same conditions. Nevertheless, the comparison shows that a solution of high $\mathrm{H}^{+}$activity and a solution of high $\mathrm{NH}_{4}^{+}$activity may both lead to a relatively similar reactive uptake coefficient. As $\left[\mathrm{NH}_{4}^{+}\right] \gg\left[\mathrm{H}^{+}\right]$in the particles in this work, a similar $\Phi_{\mathrm{OA} / \mathrm{IEPOX}}$ would also suggest that $k_{\mathrm{NH}_{4}^{+}} \ll k_{\mathrm{H}^{+}}$if the observed rate coefficient for Reaction (2) is defined as $k_{\mathrm{obs}}=k_{\mathrm{AH}} \cdot[\mathrm{AH}]$. Eddingsaas et al. (2010) estimated $k_{H^{+}} \sim$ $5 \times 10^{-2} \mathrm{M}^{-1} \mathrm{~s}^{-1}$ and Cole-Filipiak et al. (2010) determined $k_{H^{+}}=3.6 \times 10^{-2} \mathrm{M}^{-1} \mathrm{~s}^{-1}$ for IEPOX. 


\subsection{Molecular picture of OA formation from IEPOX}

\subsubsection{Cation and anion substitutions}

To further investigate the role of $\mathrm{NH}_{4}^{+}$in IEPOX ringopening reactions at near-neutral conditions, $\mathrm{NH}_{4}^{+}$was replaced by a cation that cannot act as a proton donor $\left(\mathrm{Na}^{+}\right)$. As isomer structure appears to be unimportant for uptake, only the trans isomer was used for this portion of the study. Further, many nucleophiles present in the atmosphere are known to add to the protonated epoxide to give the betahydroxy ring-opening product, for example: $\mathrm{H}_{2} \mathrm{O}$ (Solomons and Fryhle, 2004), $\mathrm{SO}_{4}^{2-}$ ions (Cavdar and Saracoglu, 2009), $\mathrm{NH}_{3}$ or amines (Clayden et al., 2001), and halide ions (Clayden et al., 2001). Thus, $\mathrm{SO}_{4}^{2-}$ was substituted by $\mathrm{Cl}^{-}$to study the anion (or nucleophile) effect.

Hydrated particles of AS $\left(\left(\mathrm{NH}_{4}\right)_{2} \mathrm{SO}_{4}\right)$, sodium sulfate $\left(\mathrm{Na}_{2} \mathrm{SO}_{4}\right)$, ammonium chloride $\left(\mathrm{NH}_{4} \mathrm{Cl}\right)$, and sodium chloride $(\mathrm{NaCl})$ were introduced into the chamber in separate experiments, followed by the introduction of trans $\beta$-IEPOX. The mixtures were allowed to equilibrate for $3.5-6 \mathrm{~h}$. The $\mathrm{RH}$ range for these reactions is $60-85 \%$, chosen at a point well above their respective efflorescence RH (Martin, 2000), so that each seed would contain a considerable fraction of liquid water. The particle size distributions for each seed type were polydisperse and unimodal, with hydrated mobility diameters in the range of $15-600 \mathrm{~nm}$ and with $60-120 \mathrm{~nm}$ peak diameters. It is expected that the hydrated particles were spherical. The size-dependent hygroscopicities of $\mathrm{AS}$ and $\mathrm{NaCl}$ are well-studied, however, the calculations of liquid water content for other seed types are subject to error based on the method we described due to limited literature data. Therefore, we opt to present results based only on the $C_{\mathrm{OA}} / C_{\mathrm{IEPOX}}$ for the comparison of inorganic seed compositions.

OA formation after particle drying, as detected by ToFAMS, is negligible for both sodium salts $(\mathrm{NaCl}$ and $\mathrm{Na}_{2} \mathrm{SO}_{4}$ ). The OA mass did not grow in response to the addition of IEPOX for the $\mathrm{Na}^{+}$-based particles (Fig. S4). Figure 4 shows the average stabilized ratios of OA formed with respect to trans $\beta$-IEPOX injected for the four inorganic salts used in this work. The atomizer solution $\mathrm{pH}$ for $\mathrm{Na}^{+}$-based seeds was also $\sim 5.5$, a typical $\mathrm{pH}$ for a water solution in equilibrium with $\mathrm{CO}_{2}$ (Reuss, 1977). The large difference in reactivity of IEPOX on $\mathrm{Na}_{2} \mathrm{SO}_{4}$ vs. $\left(\mathrm{NH}_{4}\right)_{2} \mathrm{SO}_{4}$ seeds may be attributed primarily to $\mathrm{NH}_{4}^{+}$activity, although there will be some differences in $[\mathrm{H}+]$ for the $\mathrm{NH}_{4}^{+}$-based and $\mathrm{Na}^{+}$-based seeds due to the slight dissociation of $\mathrm{NH}_{4}^{+} \leftrightarrows \mathrm{NH}_{3}$. Additionally, in light of the weak pH dependence for AS solutions, it appears likely that $\mathrm{NH}_{4}^{+}$activity is an important factor in suppressing OA formation on $\mathrm{Na}_{2} \mathrm{SO}_{4}$ seed particles. The results show that equilibrium partitioning of IEPOX, i.e., any condensed-phase mass formed from unreacted IEPOX, onto salty solutions is not competitive with reactive partitioning for OA formation.

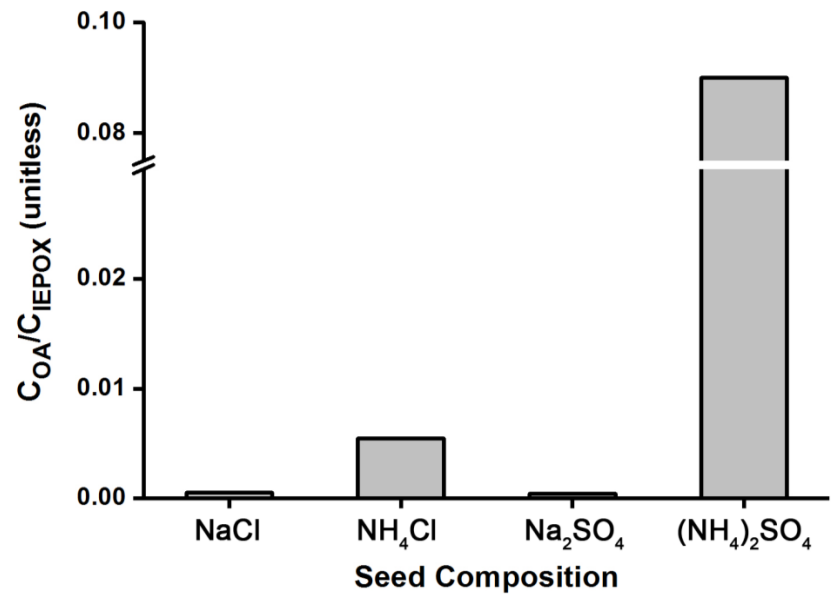

Fig. 4. Ratio of organic aerosol produced to gas-phase trans $\beta$ IEPOX injected for seeds of various compositions (RH 60-85\%).

For the ammonium salts, $\mathrm{NH}_{4} \mathrm{Cl}$ produced an order of magnitude lower mean $C_{\mathrm{OA}} / C_{\mathrm{IEPOX}}$ ratio than $\left(\mathrm{NH}_{4}\right)_{2} \mathrm{SO}_{4}$, after an approximate $2 \mathrm{~h}$ delay (Fig. S4). The modeled $\mathrm{pH}$, using E-AIM, for both ammonium salt systems is similar ( $\mathrm{pH} \sim 4-4.5$ ), and thus, the difference in reactivity may be attributed to the nucleophilic activity of $\mathrm{Cl}^{-}$compared to $\mathrm{SO}_{4}^{2-}$. Interestingly, Minerath et al. (2009) showed that acidcatalyzed ring-opening products of an epoxide with $\mathrm{Cl}^{-}$may be more efficient than $\mathrm{SO}_{4}^{2-}$. In that study, sulfuric acid was added to the $\mathrm{NaCl}+$ epoxide aqueous solution, which provide sulfate and bisulfate ions to the solution. Therefore, the results may not be directly comparable to this work. If $\mathrm{Cl}^{-}$can be a good nucleophile in aqueous solutions of IEPOX when coupled with $\mathrm{NH}_{4}^{+}$catalysis, we may expect to observe organochloride products. There was no evidence of organochloride-derived accurate mass fragments in ToFAMS data for the $\mathrm{NH}_{4} \mathrm{Cl}$ reactive uptake organics. Further, gas-phase organochlorides were not observed by the CIMS. It is possible that organochlorides are produced but are easily hydrolyzed in the aerosol liquid water due to the relatively good leaving group ability of $\mathrm{Cl}^{-}$, i.e., the hydrolysis behavior of organochlorides is more similar to that of tertiary organonitrates than that of organosulfates (Darer et al., 2011). It is also possible that organochlorides are preferentially evaporated in the diffusion drier because they might be more volatile than organosulfates or polyols. In both situations, but more so the latter, the total organic mass from the $\mathrm{NH}_{4} \mathrm{Cl}$ experiments would be underestimated by ToF-AMS. Although we did not quantify tetrols and other polyols in this work, it is expected that they are present in substantial quantities because they are the thermodynamically preferred products in the epoxide ring-opening reactions. 


\subsubsection{Henry's Law constant}

Although ToF-AMS did not observe OA formation for experiments using sodium salts $\left(\mathrm{NaCl}\right.$ and $\left.\mathrm{Na}_{2} \mathrm{SO}_{4}\right)$ after particle drying, the wall-loss-corrected SMPS data (not dried) showed a minor and stable change in particle volume upon injection of IEPOX into the chamber with hydrated $\mathrm{NaCl}$ or $\mathrm{Na}_{2} \mathrm{SO}_{4}$ seeds (Fig. S5a, shown for $\mathrm{NaCl}$ ). It is likely that the dissolved but unreacted IEPOX was removed from the condensed phase upon particle drying, which would lead to no observed OA mass in the ToF-AMS data throughout the duration of the experiment. The reversibility OA formation on the hydrated seeds indicates equilibrium-partitioning of IEPOX into the aerosol liquid water. The ratio of dissolved OA to injected IEPOX (Fig. S5b) reached a steady-state value at the end of the IEPOX injection period. Because $\mathrm{NH}_{4}^{+}$ is not present, and $\left[\mathrm{H}^{+}\right]$is not expected to be considerable in the aqueous phase, Reactions (R2) and (R4) are unimportant for this system. Further, in experiments using $\mathrm{NaCl}$ seeds, where the nucleophilicity of the solution is weaker, we are able to neglect the contribution of Reaction (R3), thereby isolating the equilibrium partitioning of IEPOX (Reaction R1).

We estimate the Henry's Law coefficient $\left(\mathrm{K}_{\mathrm{H}}\right)$ for the equilibrium partitioning of IEPOX into a briny liquid ( $\mathrm{NaCl} \sim 9 \mathrm{M}$ ionic strength) representative of atmospheric aerosol to be $3 \times 10^{7}(-50 /+100 \%) \mathrm{Matm}^{-1}$. The $\mathrm{K}_{\mathrm{H}}$ in a solution of $\mathrm{NaCl}$ may be different than the value in pure water, due to complex aqueous interactions of $\mathrm{Cl}^{-}$and $\mathrm{Na}^{+}$with water-soluble organics. As an example, the Henry's Law constant for glyoxal was measured to be $\mathrm{K}_{\mathrm{H}}=(4.19 \pm 0.87) \times 10^{5} \mathrm{M} \mathrm{atm}^{-1}$ in pure water, $1.90 \times 10^{6} \mathrm{Matm}^{-1}$ in a $0.05 \mathrm{M} \mathrm{NaCl}$ solution, and $8.50 \times 10^{5} \mathrm{M} \mathrm{atm}^{-1}$ in a $4.0 \mathrm{M} \mathrm{NaCl}$ solution at $298 \mathrm{~K}$ (Ip et al., 2009). Ip et al. (2009) attributed the increase in $\mathrm{K}_{\mathrm{H}}$ for $\mathrm{NaCl}$ solutions at low ionic strengths (compared to water) to hydrogen bonding interactions of $\mathrm{Cl}^{-}$and $\mathrm{OH}$ groups and the decrease at high ionic strength to a "salting-out" effect. The $\mathrm{K}_{\mathrm{H}}$ value for IEPOX has not been experimentally determined in the past; however, the range of $\mathrm{K}_{\mathrm{H}}$ has been estimated using the HENRYWIN model (EPA, 2008) by several studies. For example, Eddingsaas et al. (2010) estimated $\mathrm{K}_{\mathrm{H}}=2.7 \times 10^{6} \mathrm{M} \mathrm{atm}^{-1}$ using a bond contribution method, and $\mathrm{K}_{\mathrm{H}}=2.9 \times 10^{10} \mathrm{M} \mathrm{atm}^{-1}$ using a group contribution method in version 4.0 of the model. The empirical $\mathrm{K}_{\mathrm{H}}$ value reported here is within range of both estimations - closer to the bond contribution method estimate. These results provide a critical constraint in the partitioning coefficient, significantly decreasing the error associated with using $\mathrm{K}_{\mathrm{H}}$ in a quantitative manner (from 4 orders of magnitude to a factor of two).

\subsubsection{Organic composition}

A full analysis of the OA composition is outside the scope of this work. The reader is referred elsewhere for a discussion

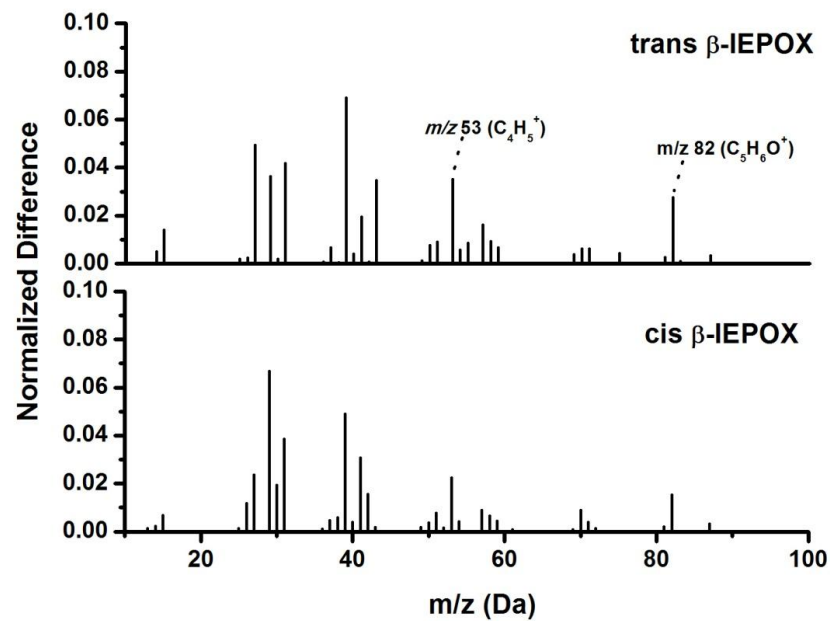

Fig. 5. ToF-AMS normalized difference spectra (composition at peak OA growth minus composition during seed injection), showing the organic composition of the OA produced by reactive uptake of the trans and cis isomers. Select nominal mass ions previously suggested to be IEPOX-derived OA tracers are labeled.

of the formation of oxygenated hydrocarbons, for example, tetrols and alkenetriols and organosulfates in the aqueous reaction of IEPOX catalyzed by acidic sulfate (Eddingsaas et al., 2010, Surratt et al., 2010). Although strong acid is absent in the systems studied in this work, we observe many similarities in the IEPOX-derived OA composition compared to the existing chamber and field results. For example, organosulfate products are abundant when hydrated AS seeds are used. The dominant ion observed in negative ion mode UPLC/ESIToFMS for AS uptake was $\mathrm{C}_{5} \mathrm{H}_{11} \mathrm{SO}_{7}^{-}$(Fig. S6), corresponding to the ring-opening trihydroxy organosulfate product of IEPOX. Derivatization was not performed in this work to detect tetrols. Organosulfate fragments were also observed in ToF-AMS (CSO family of fragments, not shown).

IEPOX-derived OA formed under near-neutral conditions in this work have ToF-AMS spectra similar to those of OA observed in the field. The suggested tracers for IEPOXderived organics, $m / z 53$ (mostly $\mathrm{C}_{4} \mathrm{H}_{5}^{+}$) and $m / z 82$ (mostly $\mathrm{C}_{5} \mathrm{H}_{6} \mathrm{O}^{+}$) (Lin et al., 2012, Robinson et al., 2011, Budisulistiorini et al., 2013), were observed in uptake experiments using both isomers. These mass fragments were proposed to originate from the electron-impact (EI) ionization of furan-derived molecules that were suggested to be formed from the acid-catalyzed rearrangement of IEPOX (Lin et al., 2013). Although mass fragments produced by EI may have multiple sources, in the pure system used in this study, $m / z 82$ was found to be a good tracer for IEPOX-derived OA. Figure 5 shows the difference between mass spectra at the end of the experiment and those at the time period prior to organic injection, corresponding to the organic fraction of the OA formed from the uptake of both isomers. The spectral ion distributions are very similar to each other 

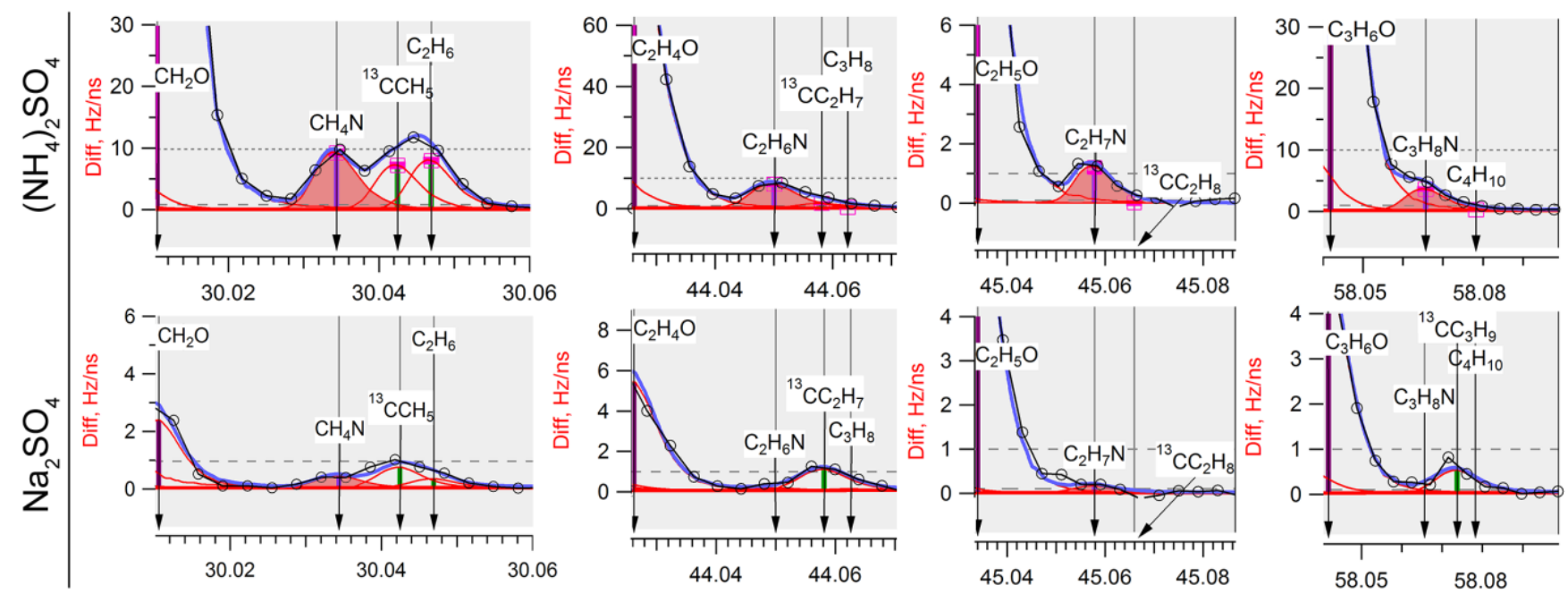

Fig. 6. ToF-AMS difference spectra (open minus closed chopper) showing organic nitrogen (amine) fragments from the reactive uptake of trans $\beta$-IEPOX onto AS vs. $\mathrm{Na}_{2} \mathrm{SO}_{4}$ seeds. Similar fragments were observed for cis $\beta$-IEPOX using $\mathrm{NH}_{4}^{+}$-based seeds and not observed in $\mathrm{Na}^{+}$-based seeds.

and $m / z \quad 53$ and $m / z 82$ constituted a substantial fraction of the total ion intensity. The ion abundance of tracer fragments increased in accordance with the growth of OA mass (Fig. S7). As $m / z 53\left(\mathrm{C}_{4} \mathrm{H}_{5}^{+}\right)$is a reduced fragment, it is also linked to hydrocarbon-like organics in chamber studies and may not be unique to IEPOX-derived OA. $\mathrm{m} / z 53$ was observed in all experiments, including those that used $\mathrm{Na}^{+}$based seeds. However, $m / z, 82$ is abundant only when $\mathrm{NH}_{4}^{+}$based seeds were used, supporting the suggestion that it can be formed though the EI fragmentation of an IEPOX-derived ring-opening product in ToF-AMS.

A unique aspect of the $\mathrm{NH}_{4}^{+}$-catalyzed ring-opening reaction of IEPOX is the minor possibility of nucleophilic addition by $\mathrm{NH}_{3}$, instead of reforming $\mathrm{NH}_{4}^{+}$after neutralizing the addition of another nucleophile. Figure 6 shows ion peaks for organic fragments containing $\mathrm{C}-\mathrm{N}$ bonds observed in ToFAMS data from the uptake of trans $\beta$-IEPOX onto AS vs. $\mathrm{Na}_{2} \mathrm{SO}_{4}$ seeds. The same $\mathrm{C}-\mathrm{N}$ fragments were observed in cis $\beta$-IEPOX experiments using AS. These $\mathrm{C}-\mathrm{N}$ fragments were not initially present in the AS seeds, and grow linearly following the introduction of IEPOX. Individual C-N fragments correlate well (Fig. S8, linear fit $R^{2}=0.69-0.88$ ) with the $m / z 82$ IEPOX-derived OA tracer fragment $\left(\mathrm{C}_{5} \mathrm{H}_{6} \mathrm{O}^{+}\right)$, suggesting that the reaction of IEPOX is responsible for the presence of these amines. Comparatively, C-N type fragments were negligible or non-existent in uptake experiments from $\mathrm{Na}^{+}$-based seeds. The identification of amines is tentative; however, to the best of our knowledge, this is the first suggestion of amine formation from IEPOX. As organic nitrogen compounds also give rise to non-nitrogenous mass fragments in ToF-AMS, it is not possible to estimate a mass concentration for the amines in this work. However, the C$\mathrm{N}$ family of fragments comprised approximately $10 \%$ of the
$\mathrm{C}_{5} \mathrm{H}_{6} \mathrm{O}^{+}$signal, an indication that amine formation may not be negligible. The formation of organic nitrogen from the IEPOX $+\mathrm{NH}_{4}^{+}$reaction has important implications in the atmosphere as the ring-opening reaction of epoxides with amines should be more efficient than with $\mathrm{NH}_{3}$ (Azizi and Saidi, 2005). Further investigations may provide more insight on the source of organic nitrogen from the atmospheric reactions of epoxides.

\section{Summary and atmospheric implications}

It was demonstrated here that the conversion of IEPOX to organic aerosol (OA) depends on the coupled relationship between the inorganic composition and liquid water content of the particle $\left(P_{\mathrm{LWC}}\right)$. The inorganic composition governs the catalyst and nucleophile characteristics, and $P_{\mathrm{LWC}}$ provides a reaction medium for the partitioning of IEPOX and controls the activities of all the aqueous components. The weak dependence on $\mathrm{pH}$ and the strong dependence on nucleophile activity and particle liquid water suggest that the IEPOX reactions in hydrated ammonium salts are nucleophile-limited, rather than catalyst-limited.

We showed that the equilibrium partitioning (Reaction 1) and the rate-limiting step of IEPOX activation (Reaction 2) do not proceed in the absence of liquid water; however, increasing the pure water content does not necessarily increase the reactive partitioning coefficient due to various dilution effects. When the inorganic particle is hydrated, the OA conversion is then determined by the catalyst and nucleophile activities. The rate of OA formation incorporates both Reactions (R2) and (R3), as illustrated by the cation and anion substitution case studies. In the hydrated $\mathrm{Na}_{2} \mathrm{SO}_{4}$ experiment, there was high activity of a relatively 
good nucleophile, but a good catalyst was absent. Therefore, the formation of OA, i.e., the ring-opening product, was not observed because the equilibrium of Reaction (R2) favors $\operatorname{IEPOX}_{(\mathrm{aq})}$. The aqueous IEPOX mass that partitioned from the gas phase $\left(\mathrm{K}_{\mathrm{H}}\right)$ onto the hydrated $\mathrm{Na}^{+}$-based seeds was removed from the condensed phase following the evaporation of water. In the hydrated $\mathrm{NH}_{4} \mathrm{Cl}$ experiment, there was high activity of a good catalyst but possibly a poorer nucleophile than sulfate ion. A smaller quantity of OA formed because the rate of Reaction (R3) was slow, which was further supported by the observed $2 \mathrm{~h}$ delay in OA formation. Only when $P_{\mathrm{LWC}}, \mathrm{NH}_{4}^{+}$activity, and $\mathrm{SO}_{4}^{2-}$ activity are all significant, as in the case of hydrated $\left(\mathrm{NH}_{4}\right)_{2} \mathrm{SO}_{4}$ seeds, is the OA formation efficient and prompt. The OA mass formed from IEPOX uptake onto $1: 1 \mathrm{MgSO}_{4}: \mathrm{H}_{2} \mathrm{SO}_{4}$ seeds $(\mathrm{RH}<5 \%)$ from previous studies may also be explained in terms of these conditions, as $P_{\text {LWC }}(\sim 30 \%)$, catalyst $\left(\mathrm{H}^{+}\right)$activity and nucleophile $\left(\mathrm{SO}_{4}^{2-}\right)$ activity were all sufficiently high in the particle.

In the atmosphere, relationships of water-soluble OA with $P_{\text {LWC }}$ may be different and more difficult to interpret compared to laboratory studies because an increase in the $P_{\text {LWC }}$ of atmospheric particles is often accompanied by the copartitioning of water-soluble organic and inorganic compounds. The abundance of water-soluble organic compounds in the Southeast USA has been observed to be proportional to the liquid water contents of particles (Hennigan et al., 2008, 2009, Carlton and Turpin, 2013). In contrast, a weak correlation of modeled $P_{\text {LWC }}$ with the abundance of IEPOX-derived OA tracers has also been observed, in the same geographical region (Budisulistiorini et al., 2013). The results of this work may not be directly comparable to field observations, however, they do not necessarily conflict. Particles may experience multiple hydration/evaporation cycles in the atmosphere, and the majority of particles likely contain liquid water at some point during their long lifetimes. The OA produced from IEPOX reactive uptake onto AS is irreversible (not removed from particle drying in this work), and depending on whether it had been sampled in the atmosphere before or after an evaporation cycle, the apparent correlation of IEPOX-derived OA with $P_{\text {LWC }}$ would be different. Consequently, systematic studies in the laboratory are important for elucidating observations from the field.

Our results offer an alternate explanation to the abundance of IEPOX-derived OA tracers when the free $\mathrm{H}^{+}$acidity in particles is modeled to be low (Lin et al., 2013). It has been suggested that the reason for the weak correlation with acidity is the reaction of an acidic seed particle with IEPOX to form organosulfates, which affects the particle acidity over time (Budisulistiorini et al., 2013). We show here that particle acidity does not appear to be important for the IEPOX + AS system if particle liquid water is present, in that highly acidic seeds and weakly acidic AS seeds both have high potential to form OA from IEPOX reactive partitioning. The apparent correlation between OA mass from IEPOX and $\mathrm{P}_{\mathrm{LWC}}$,

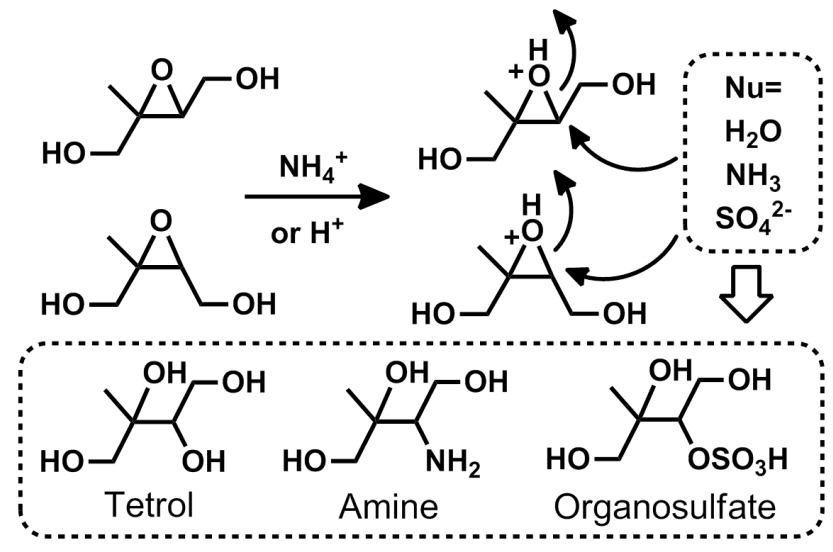

Scheme 2 Addition of weak nucleophiles in the aqueous $\mathrm{NH}_{4}^{+}-$ and $\mathrm{H}^{+}$-catalyzed ring opening of IEPOX to form low-volatility organic compounds.

ammonium or acidity may be weak whenever water or catalyst concentrations are not limited; thus, in regions with high AS loading and RH, there should be a higher correlation with sulfate. This result would suggest that the OA formation process from IEPOX is insensitive to changes in the degree of neutralization of the particles in many ASdominated areas, including the Southeast USA. The typical $\left[\mathrm{NH}_{4}^{+}\right]$is several orders of magnitude larger than $\left[\mathrm{H}^{+}\right]$ in atmospheric particles, making it very likely to activate the IEPOX ring-opening reaction. Current models consider only $\mathrm{H}^{+}$and $\mathrm{HSO}_{4}^{-}$activity (McNeill et al., 2012, Pye et al., 2013), likely owing to the lack of experimental data describing the $\mathrm{NH}_{4}^{+}$-initiated reaction with IEPOX, for example, kinetic coefficients like $k_{\mathrm{NH}_{4}^{+}}$. Future experimental and modeling studies should consider the $\mathrm{NH}_{4}^{+}$activity of a particle, in addition to the $\mathrm{H}^{+}$and $\mathrm{HSO}_{4}^{-}$activity, for a more-accurate representation of OA formation from IEPOX.

An updated reaction mechanism appears in Scheme 2, in which $\mathrm{NH}_{4}^{+}$and $\mathrm{H}^{+}$are shown to donate a proton to the epoxide oxygen, followed by nucleophilic addition to form oxygenated hydrocarbons, ammonia (or amines), and organosulfates. The ability of $\mathrm{NH}_{4}^{+}$to catalyze a nucleophilic addition reaction is not unprecedented, as $\mathrm{NH}_{4}^{+}$can protonate aldehydes to facilitate nucleophilic addition (Noziere et al., 2009), and the high ring strain of an epoxide should provide an even greater thermodynamic motivation for the reaction. Indeed, due to the strain of epoxides, ring opening is chemically facile and may be promoted by a wide range of aqueous chemical species and conditions common in atmospheric aerosols, in addition to $\mathrm{H}^{+}$and $\mathrm{NH}_{4}^{+}$. For example, Lewis acids such as iron $\left(\mathrm{Fe}^{3+}\right)$ (Iranpoor and Salehi, 1994) and copper $\left(\mathrm{Cu}^{2+}\right)$ (Muzart and Riahi, 1992) ions may be even stronger catalysts. Furthermore, the reaction may proceed with no added catalyst, for example, in the presence 
of amines (Azizi and Saidi, 2005) or even hot water $\left(60^{\circ} \mathrm{C}\right)$ (Wang et al., 2008). The nucleophiles for these reactions may be water, amines or ammonia, thiols, sulfate ions, nitrate ion, halide ions, carboxylic acids, and alcohols (Iranpoor et al., 1996, Jacobsen et al., 1997, Clayden et al., 2001). Because of the diversity in the composition of atmospheric aerosols and fog/cloud droplets (Graedel and Weschler, 1981), the distribution of IEPOX-derived products in nature may be more complex and varied than currently believed.

\section{Supplementary material related to this article is available online at http://www.atmos-chem-phys.net/14/ 3497/2014/acp-14-3497-2014-supplement.pdf.}

Acknowledgements. This research was supported by the National Science Foundation (NSF) grants AGS-1057183 and AGS1240604. TBN acknowledges funding from the NSF Postdoctoral Research Fellowship program, award AGS-1331360, and from the Foster and Coco Stanback Postdoctoral Fellowship. We are grateful for research support provided by the Brian Stoltz Group at Caltech for the syntheses of the $\beta$-IEPOX isomers, with special acknowledgement to Dr. Nathan Bennett. We thank Dr. Nathan Dalleska, director of the Caltech Environmental Analysis Center (EAC), for his assistance with the UPLC/ESI-ToFMS analyses.

Edited by: V. F. McNeill

\section{References}

Aiken, A. C., Decarlo, P. F., Kroll, J. H., Worsnop, D. R., Huffman, J. A., Docherty, K. S., Ulbrich, I. M., Mohr, C., Kimmel, J. R., Sueper, D., Sun, Y., Zhang, Q., Trimborn, A., Northway, M., Ziemann, P. J., Canagaratna, M. R., Onasch, T. B., Alfarra, M. R., Prevot, A. S. H., Dommen, J., Duplissy, J., Metzger, A., Baltensperger, U., and Jimenez, J. L.: O/C and OM/OC ratios of primary, secondary, and ambient organic aerosols with high-resolution time-of-flight aerosol mass spectrometry, Environ. Sci. Technol., 42, 4478-4485, 2008.

Allan, J. D., Delia, A. E., Coe, H., Bower, K. N., Alfarra, M. R., Jimenez, J. L., Middlebrook, A. M., Drewnick, F., Onasch, T. B., and Canagaratna, M. R.: A generalised method for the extraction of chemically resolved mass spectra from aerodyne aerosol mass spectrometer data, J. Aerosol. Sci., 35, 909-922, 2004.

Azizi, N. and Saidi, M. R.: Highly chemoselective addition of amines to epoxides in water, Org. Lett., 7, 3649-3651, 2005.

Bates, K. H., Crounse, J. D., St. Clair, J. M., Bennett, N. B., Nguyen, T. B., Seinfeld, J. H., Stoltz, B. M., and Wennberg, P. O.: Gas phase production and loss of isoprene epoxydiols. J. Phys. Chem. A, 118, 1237-1246, doi:10.1021/jp4107958, 2014.

Biskos, G., Paulsen, D., Russell, L. M., Buseck, P. R., and Martin, S. T.: Prompt deliquescence and efflorescence of aerosol nanoparticles, Atmos. Chem. Phys., 6, 4633-4642, 10, http://www.atmos-chem-phys.net/6/4633/10/.5194/acp-6-46332006, 2006.

Bones, D. L., Henricksen, D. K., Mang, S. A., Gonsior, M., Bateman, A. P., Nguyen, T. B., Cooper, W. J., and Nizkorodov, S. A.:
Appearance of strong absorbers and fluorophores in limonene$\mathrm{O}_{3}$ secondary organic aerosol due to $\mathrm{NH}_{4}^{+}$-mediated chemical aging over long time scales, J. Geophys. Res., 115, D05203, doi:10.01029/02009jd012864, 2010.

Budisulistiorini, S. H., Canagaratna, M. R., Croteau, P. L., Marth, W. J., Baumann, K., Edgerton, E. S., Shaw, S. L., Knipping, E. M., Worsnop, D. R., Jayne, J. T., Gold, A., and Surratt, J. D.: Real-time continuous characterization of secondary organic aerosol derived from isoprene epoxydiols in downtown Atlanta, Georgia, using the Aerodyne aerosol chemical speciation monitor, Environ. Sci. Technol., 47, 5686-5694, 2013.

Carlton, A. G. and Turpin, B. J.: Particle partitioning potential of organic compounds is highest in the Eastern US and driven by anthropogenic water, Atmos. Chem. Phys., 13, 10203-10214, doi:10.5194/acp-13-10203-2013, 2013.

Cavdar, H., and Saracoglu, N.: Ring opening of epoxides with $\mathrm{NaHSO}_{4}$ : Isolation of $\beta$-hydroxy sulfate esters and an effective synthesis for trans-diols, Tetrahedron, 65, 985-989, 2009.

Chan, M. N., Surratt, J. D., Claeys, M., Edgerton, E. S., Tanner, R. L., Shaw, S. L., Zheng, M., Knipping, E. M., Eddingsaas, N. C., Wennberg, P. O., and Seinfeld, J. H.: Characterization and quantification of isoprene-derived epoxydiols in ambient aerosol in the southeastern united states, Environ. Sci. Technol., 44, 45904596, 2010.

Clayden, J., Greeves, N., Warren, S., and Wothers, P.: Organic chemistry, Oxford University Press, 386 pp., ISBN 978-380-319850346-850340, 2001.

Clegg, S. L., Brimblecombe, P., and Wexler, A. S.: Thermodynamic model of the system $\mathrm{H}^{+}-\mathrm{NH}_{4}^{+}-\mathrm{SO}_{4}^{2-}-\mathrm{NO}_{3}-\mathrm{H}_{2} \mathrm{O}$ at tropospheric temperatures, J. Phys. Chem. A, 102, 2137-2154, 1998.

Cole-Filipiak, N. C., O'Connor, A. E., and Elrod, M. J.: Kinetics of the hydrolysis of atmospherically relevant isoprene-derived hydroxy epoxides, Environ. Sci. Technol., 44, 6718-6723, 2010.

Crounse, J. D., McKinney, K. A., Kwan, A. J., and Wennberg, P. O.: Measurement of gas-phase hydroperoxides by chemical ionization mass spectrometry, Anal. Chem., 78, 6726-6732, 2006.

Darer, A. I., Cole-Filipiak, N. C., O'Connor, A. E., and Elrod, M. J.: Formation and dtability of stmospherically televant isoprenederived organosulfates and organonitrates, Environ. Sci. Technol., 45, 1895-1902, 2011.

De Haan, D. O., Hawkins, L. N., Kononenko, J. A., Turley, J. J., Corrigan, A. L., Tolbert, M. A., and Jimenez, J. L.: Formation of nitrogen-containing oligomers by methylglyoxal and amines in simulated evaporating cloud droplets, Environ. Sci. Technol., 45, 984-991, 2011.

Docherty, K. S., Jaoui, M., Corse, E., Jimenez, J. L., Offenberg, J. H., Lewandowski, M., and Kleindienst, T. E.: Collection efficiency of the aerosol mass spectrometer for chamber-generated secondary organic aerosols, Aerosol Sci. Technol., 47, 294-309, 2013.

Eddingsaas, N. C., VanderVelde, D. G., and Wennberg, P. O.: Kinetics and products of the acid-catalyzed ring-opening of atmospherically relevant butyl epoxy alcohols, J. Phys. Chem. A, 114, 8106-8113, 2010.

EPA: Estimation programs interface for microsoft mindows xp v4.0, US EPA, 2008.

Ervens, B. and Volkamer, R.: Glyoxal processing by aerosol multiphase chemistry: towards a kinetic modeling framework of sec- 
ondary organic aerosol formation in aqueous particles, Atmos. Chem. Phys., 10, 8219-8244, doi:10.5194/acp-10-8219-2010, 2010.

Froyd, K. D., Murphy, S. M., Murphy, D. M., de Gouw, J. A., Eddingsaas, N. C., and Wennberg, P. O.: Contribution of isoprene-derived organosulfates to free tropospheric aerosol mass, Proc. Natl. Acad. Sci., 107, 21360-21365, doi:10.1073/pnas.1012561107, 2010.

Graedel, T. E. and Weschler, C. J.: Chemistry within aqueous atmospheric aerosols and raindrops, Rev. Geophys., 19, 505-539, 1981.

Gregoire, P.: Implications of ambient ammonia on aerosol acidity and reactive nitrogen measurements, MS, Department of Chemistry, University of Toronto, Toronto, Ontario, Canada, 82 pp., 2013.

Griffith, D. W. T.: Synthetic calibration and quantitative analysis of gas-phase FT-IR spectra, Appl. Spectrosc., 50, 59-70, 1996.

Hatch, L. E., Creamean, J. M., Ault, A. P., Surratt, J. D., Chan, M. N., Seinfeld, J. H., Edgerton, E. S., Su, Y., and Prather, K. A.: Measurements of isoprene-derived organosulfates in ambient aerosols by aerosol time-of-flight mass spectrometry - Part 2: Temporal variability and formation mechanisms, Environ. Sci. Technol., 45, 8648-8655, 2011.

Hennigan, C. J., Bergin, M. H., Dibb, J. E., and Weber, R. J.: Enhanced secondary organic aerosol formation due to water uptake by fine particles, Geophys. Res. Lett., 35, L18801, doi:10.1029/2008GL035046, 2008.

Hennigan, C. J., Bergin, M. H., Russell, A. G., Nenes, A., and Weber, R. J.: Gas/particle partitioning of water-soluble organic aerosol in Atlanta, Atmos. Chem. Phys., 9, 3613-3628, doi:10.5194/acp-9-3613-2009, 2009.

Hu, D., Qiao, L., Chen, J., Ye, X., Yang, X., Cheng, T., and Fang, W.: Hygroscopicity of inorganic aerosols: Size and relative humidity effects on the growth factor, Aerosol. Air. Qual. Res., 10, 255-264, 2010.

Ip, H. S. S., Huang, X. H. H., and Yu, J. Z.: Effective henry's law constants of glyoxal, glyoxylic acid, and glycolic acid, Geophys. Res. Lett., 36, L01802, doi:10.1029/2008g1036212, 2009.

Iranpoor, N. and Salehi, P.: Highly efficient, regio-and stereoselective alcoholysis of epoxides catalyzed with iron (iii) chloride, Synthesis, 1994, 1152-1154, 1994.

Iranpoor, N., Tarrian, T., and Movahedi, Z.: $\mathrm{FeCl}_{3} \cdot 6 \mathrm{H}_{2} \mathrm{O}$ supported on $\mathrm{SiO}_{2}$ catalysed ring opening of epoxides with alcohols, acetic acid, water, chloride, bromide and nitrate ions, Synthesis, 1996, 1473-1476, 1996.

Jacobsen, E. N., Kakiuchi, F., Konsler, R. G., Larrow, J. F., and Tokunaga, M.: Enantioselective catalytic ring opening of epoxides with carboxylic acids, Tetrahedron Lett., 38, 773-776, 1997.

Kampf, C. J., Waxman, E. M., Slowik, J. G., Dommen, J., Pfaffenberger, L., Praplan, A. P., Prévôt, A. S. H., Baltensperger, U., Hoffmann, T., and Volkamer, R.: Effective Henry's law partitioning and the salting constant of glyoxal in aerosols containing sulfate, Environ. Sci. Technol., 47, 4236-4244, 2013.

Lee, C.-T. and Hsu, W.-C.: The measurement of liquid water mass associated with collected hygroscopic particles, J. Aerosol. Sci., 31, 189-197, 2000.

Lin, Y.-H., Zhang, Z., Docherty, K. S., Zhang, H., Budisulistiorini, S. H., Rubitschun, C. L., Shaw, S. L., Knipping, E. M., Edgerton, E. S., Kleindienst, T. E., Gold, A., and Surratt, J. D.: Isoprene epoxydiols as precursors to secondary organic aerosol formation: Acid-catalyzed reactive uptake studies with authentic compounds, Environ. Sci. Technol., 46, 250-258, 2012.

Lin, Y.-H., Knipping, E. M., Edgerton, E. S., Shaw, S. L., and Surratt, J. D.: Investigating the influences of $\mathrm{SO} 2$ and $\mathrm{NH} 3$ levels on isoprene-derived secondary organic aerosol formation using conditional sampling approaches, Atmos. Chem. Phys., 13, 84578470, doi:10.5194/acp-13-8457-2013, 2013.

Loza, C. L., Chan, A. W. H., Galloway, M. M., Keutsch, F. N., Flagan, R. C., and Seinfeld, J. H.: Characterization of vapor wall loss in laboratory chambers, Environ. Sci. Technol., 44, 5074-5078, 2010.

Loza, C. L., Chhabra, P. S., Yee, L. D., Craven, J. S., Flagan, R. C., and Seinfeld, J. H.: Chemical aging of m-xylene secondary organic aerosol: laboratory chamber study, Atmos. Chem. Phys., 12, 151-167, doi:10.5194/acp-12-151-2012, 2012.

Martin, S. T.: Phase transitions of aqueous atmospheric particles, Chem. Rev., 100, 3403-3453, 2000.

Matthew, B. M., Middlebrook, A. M., and Onasch, T. B.: Collection efficiencies in an Aerodyne aerosol mass spectrometer as a function of particle phase for laboratory generated aerosols, Aerosol. Sci. Technol., 42, 884-898, 2008.

McNeill, V. F., Woo, J. L., Kim, D. D., Schwier, A. N., Wannell, N. J., Sumner, A. J., and Barakat, J. M.: Aqueous-phase secondary organic aerosol and organosulfate formation in atmospheric aerosols: A modeling study, Environ. Sci. Technol., 46, 8075-8081, 2012.

Minerath, E. C., Casale, M. T., and Elrod, M. J.: Kinetics feasibility study of alcohol sulfate esterification reactions in tropospheric aerosols, Environ. Sci. Technol., 42, 4410-4415, 2008.

Minerath, E. C., Schultz, M. P., and Elrod, M. J.: Kinetics of the reactions of isoprene-derived epoxides in model tropospheric aerosol solutions, Environ. Sci. Technol., 43, 8133-8139, 2009.

Muzart, J. and Riahi, A.: Palladium- and light-enhanced ringopening of oxiranes by copper chloride, J. Organomet. Chem., 433, 323-336, 1992.

Nguyen, T. B., Lee, P. B., Updyke, K. M., Bones, D. L., Laskin, J., Laskin, A., and Nizkorodov, S. A.: Formation of nitrogenand sulfur-containing light-absorbing compounds accelerated by evaporation of water from secondary organic aerosols, J. Geophys. Res., 117, D01207, doi:10.01029/02011JD016944, 2012.

Nguyen, T. B., Laskin, A., Laskin, J., Nizkorodov, S. A., Brown carbon formation from ketoaldehydes of biogenic monoterpenes, Faraday Discuss., 165, 473-494, 2013.

Noziere, B., Dziedzic, P., and Cordova, A.: Products and kinetics of the liquid-phase reaction of glyoxal catalyzed by ammonium ions $\left(\mathrm{NH}_{4}^{+}\right)$, J. Phys. Chem. A, 113, 231-237, 2009.

Paulot, F., Crounse, J. D., Kjaergaard, H. G., Kroll, J. H., Seinfeld, J. H., and Wennberg, P. O.: Isoprene photooxidation: new insights into the production of acids and organic nitrates, Atmos. Chem. Phys., 9, 1479-1501, doi:10.5194/acp-9-1479-2009, 2009a.

Paulot, F., Crounse, J. D., Kjaergaard, H. G., Kurten, A., St. Clair, J. M., Seinfeld, J. H., and Wennberg, P. O.: Unexpected epoxide formation in the gas-phase photooxidation of isoprene, Science, 325, 730-733, 2009b.

Pye, H. O. T., Pinder, R. W., Piletic, I. R., Xie, Y., Capps, S. L., Lin, Y.-H., Surratt, J. D., Zhang, Z., Gold, A., Luecken, D. J., Hutzell, W. T., Jaoui, M., Offenberg, J. H., Kleindienst, T. E., Lewandowski, M., and Edney, E. O.: Epoxide pathways improve 
model predictions of isoprene markers and reveal key role of acidity in aerosol formation. Environ. Sci. Technol., 47, 1105611064, 2013.

Reuss, J.: Chemical and biological relationships relevant to the effect of acid rainfall on the soil-plant system, Water Air Soil Pollut., 7, 461-478, 1977.

Robinson, N. H., Hamilton, J. F., Allan, J. D., Langford, B., Oram, D. E., Chen, Q., Docherty, K., Farmer, D. K., Jimenez, J. L., Ward, M. W., Hewitt, C. N., Barley, M. H., Jenkin, M. E., Rickard, A. R., Martin, S. T., McFiggans, G., and Coe, H.: Evidence for a significant proportion of Secondary Organic Aerosol from isoprene above a maritime tropical forest, Atmos. Chem. Phys., 11, 1039-1050, doi:10.5194/acp-11-1039-2011, 2011.

Rothman, L. S., Gordon, I. E., Barbe, A., Benner, D. C., Bernath, P. F., Birk, M., Boudon, V., Brown, L. R., Campargue, A., and Champion, J.-P.: The HITRAN 2008 molecular spectroscopic database, J. Quant. Spectrosc. Rad. Transf., 110, 533-572, 2009.

Sareen, N., Schwier, A. N., Shapiro, E. L., Mitroo, D., and McNeill, V. F.: Secondary organic material formed by methylglyoxal in aqueous aerosol mimics, Atmos. Chem. Phys., 10, 997-1016, doi:10.5194/acp-10-997-2010, 2010.

Seinfeld, J. H. and Pandis, S. N.: Atmospheric chemistry and physics: From air pollution to climate change, Wiley, 2006.

Solomons, T. W. G. and Fryhle, C. B.: Organic chemistry, 8 ed., John Wiley \& Sons, Inc., Hoboken, NJ, 1255 pp., 2004.

St. Clair, J. M., McCabe, D. C., Crounse, J. D., Steiner, U., and Wennberg, P. O.: Chemical ionization tandem mass spectrometer for the in situ measurement of methyl hydrogen peroxide, Rev. Sci. Instrum., 81, 094102-094106, 2010.

Surratt, J., Chan, A. W. H., Eddingsaas, N. C., Chan, M., Loza, C. L., Kwan, A. J., Hersey, S. P., Flagan, R. C., Wennberg, P. O., and Seinfeld, J. H.: Reactive intermediates revealed in secondary organic aerosol formation from isoprene, Proc. Natl. Acad. Sci., 107, 6640-6645, 2010.
Surratt, J. D., Lewandowski, M., Offenberg, J. H., Jaoui, M., Kleindienst, T. E., Edney, E. O., and Seinfeld, J. H.: Effect of acidity on secondary organic aerosol formation from isoprene, Environ. Sci. Technol., 41, 5363-5369, 2007.

Wang, Z., Cui, Y.-T., Xu, Z.-B., and Qu, J.: Hot water-promoted ring-opening of epoxides and aziridines by water and other nucleopliles, J. Org. Chem., 73, 2270-2274, 2008.

Xiong, J. Q., Zhong, M., Fang, C., Chen, L. C., and Lippmann, M.: Influence of organic films on the hygroscopicity of ultrafine sulfuric acid aerosol, Environ. Sci. Technol., 32, 3536-3541, 1998.

Yu, G., Bayer, A. R., Galloway, M. M., Korshavn, K. J., Fry, C. G., and Keutsch, F. N.: Glyoxal in aqueous ammonium sulfate solutions: Products, kinetics and hydration effects, Environ. Sci. Technol., 45, 6336-6342, 2011.

Zhang, Z., Lin, Y. H., Zhang, H., Surratt, J. D., Ball, L. M., and Gold, A.: Technical note: Synthesis of isoprene atmospheric oxidation products: Isomeric epoxydiols and the rearrangement products cis- and trans-3-methyl-3,4-dihydroxytetrahydrofuran, Atmos. Chem. Phys., 12, 8529-8535, doi:10.5194/acp-12-85292012, 2012.

Zuend, A., Marcolli, C., Luo, B. P., and Peter, T.: A thermodynamic model of mixed organic-inorganic aerosols to predict activity coefficients, Atmos. Chem. Phys., 8, 4559-4593, doi:10.5194/acp8-4559-2008, 2008.

Zuend, A., Marcolli, C., Booth, A. M., Lienhard, D. M., Soonsin, V., Krieger, U. K., Topping, D. O., McFiggans, G., Peter, T., and Seinfeld, J. H.: New and extended parameterization of the thermodynamic model aiomfac: Calculation of activity coefficients for organic-inorganic mixtures containing carboxyl, hydroxyl, carbonyl, ether, ester, alkenyl, alkyl, and aromatic functional groups, Atmos. Chem. Phys., 11, 9155-9206, doi:10.5194/acp-11-91552011, 2011. 